\title{
The Economic Complexity of US Metropolitan Areas
}

\author{
By Benedikt S. L. Fritz and Robert A. Manduca* \\ Published in Regional Studies, 2021. This is the last draft \\ version (the version submitted to the journal before accept- \\ ance). https://doi.org/10.1080/00343404.2021.1884215 We cal- \\ culate measures of economic complexity for US metropolitan areas \\ for the years 1998-2015 based on employment data. We show that \\ the concept translates well to the regional setting and to local and \\ traded industries. Large cities and the Northeast have the highest \\ complexity, while most traded industries are more complex than \\ local ones. In cross sections, metropolitan complexity was associ- \\ ated with higher incomes, though to a lesser extent recently than \\ in the past. However, within-city increases in complexity are as- \\ sociated with income decreases. Our findings highlight the need \\ for caution when interpreting the relationship between complexity \\ and socioeconomic outcomes. Keywords: Economic Complex- \\ ity; USA; Urban Economic Development; Income; Economic Geo- \\ graphy
}

\section{Introduction}

Measures of economic complexity, which characterize and analyze economies on the basis of their productive structures, are a widely used way of studying national economies (Hidalgo and Hausmann, 2009; Tacchella et al., 2012). In recent years, there have been increasing attempts to adapt them to the study of subnational and metropolitan regions.

Initial versions of these metrics have been implemented at the subnational level in China, Australia, Mexico, Russia, New Zealand, Italy, and the United States based on different kinds of data, such as patents, exports, and employment (Gao and Zhou, 2018; Reynolds et al., 2018; Chávez et al., 2017; Lyubimov et al., 2018; Mealy et al., 2019; Gomez-Lievano and Patterson-Lomba, 2019; Davies and Maré, 2019; Balland and Rigby, 2017). These applications of regional complexity measures join a strong tradition of analyzing the productive structure of sub-national economic units in the field of evolutionary economic geography (see Neffke, 2009; Neffke et al., 2011; Frenken et al., 2007). Measures of economic complexity are also being used in the policy sphere as indicators for future growth potential (Escobari et al., 2019; Balland et al., 2018) and, for example, have become commonly used by Chile's main state funding agency (CORFO, 2018).

However, key questions remain about the applicability of methods designed for countries to the subnational setting. Additionally, there are concerns as to whether these methods are extendable to service sectors, which dominate the economies of most developed countries (Buera and Kaboski, 2012; Stojkoski et al.,

* Fritz: Zeppelin University, Am Seemooser Horn 20, 88045 Friedrichshafen, Germany, b.fritz@zeppelin-university.net. Manduca: University of Michigan, Department of Sociology, 500 South State Street, Ann Arbor, MI 48109, rmanduca@umich.edu 
2016), and to local industries as well as the traded industries that they were developed for.

In this paper, we extend the research on economic complexity by exploring three questions: a) Is the concept of economic complexity transferable to the regional context and if so, how is it best implemented; b) what can we learn about the economic geography of the United States, and its evolution over time, through this measure; and c) what is the predictive potential of such measures for regional growth?

We produce economic complexity measures for metropolitan areas in the United States between 1998 and 2015. Using employment data from the US Census County Business Patterns, we are able to include almost all types of economic activity in the country. We show that the spatial distribution of economic activity across US metro areas is suitable for economic complexity analysis, in line with previous results. Major cities with developed economies tend to have industries of all types, common as well as specialised: Los Angeles produces hand bags as well as guided missiles. But less developed metros tend to have only common industries. This pattern of "nestedness," which is well documented across countries (Bustos et al., 2012), is core to American economic geography. This finding holds for both local industries (e.g. those aimed at within-region demand, such as bakeries) as well as traded ones (e.g. those aimed at cross-region demand, such as guided missiles and handbags), so we argue that both should be included in complexity analysis.

We also show that the differences between the two most prominent competing economic complexity algorithms - ECI and Fitness (Albeaik et al., 2017a; Pietronero et al., 2017) - are relatively small in the context of the United States. More consequential is the method for determining the presence of an industry in a region. In contrast to previous work that typically considers industries present only if they have a higher than average footprint, we argue for a simple measure of presence based on whether total industry employment in a region exceeds a raw threshold of 50 employees. Compared to the standard approach based on the location quotient (LQ), this approach is better able to capture the myriad capabilities of large and diverse cities, particularly in industries that are known to scale sublinearly with city size (Youn et al., 2016).

We find that the highest complexity areas are major cities, especially Los Angeles, New York, and Chicago, while traded industries tend to rate higher on complexity than local ones. The Northeast of the US emerges as the most complex part of the country on average, though the stronger distinction is between metropolitan and rural areas. Regions were highly stable in their economic complexity over our sample period: the Pearson correlation between ECI in 1998 and that in 2015 was 0.95 . In cross-sectional regressions, cities with higher complexity have significantly higher higher per capita incomes, controlling for a number of social, economic, and institutional characteristics. However, this relationship has weakened over time, largely because of income growth in low-complexity areas, 
particularly those with large resource extraction industries. This income growth has occurred without corresponding changes in the economic complexity of these regions, weakening the overall relationship. This changing relationship highlights the contingent nature of any connections between regional productive structure and income, which is determined by macroeconomic context and political institutions as well as productive capacity. Results on within-region changes in income and complexity, which also show a fluctuating and eventually even negative relationship over time, emphasize the importance of caution when making claims about any fundamental relationship between productive structure and income.

The rest of the paper is organised as follows: The next section gives a short review of previous research on economic complexity and regional economic development. The following sections introduce the data and the complexity methodology and discuss several theoretical and methodological challenges associated with constructing a subnational version of complexity. After analysing the general transferability of economic complexity into the regional context, we conduct and discuss our regression analyses. The paper ends with a summary and implications for future research.

\section{Literature Review}

A. Studying Productive Structures: The Capabilities Approach

Economic complexity measures draw on what researchers have termed the "capabilities approach" to understanding economic development (Hidalgo and Hausmann, 2009; Hausmann et al., 2013). In this approach, an economy is seen as a system of knowledge accumulation, and its prosperity depends on its ability to transform that knowledge into useful products (Hidalgo, 2015). Productive knowledge is thought to exist in discrete units, or capabilities, such as the capability to weld metal or the capability to spin thread. These capabilities are combined to produce the prime economic outputs of the system, its products and services (Hidalgo et al., 2007; Hidalgo and Hausmann, 2009).

The key claim of the capabilities approach is that while it is typically impossible to directly observe capabilities, they can be inferred from the presence of industries: If an economy is able to competitively produce handbags, say, then it must have access to whatever capabilities go into handbag production - from sewing and tanning to fashion design and factory organisation. By studying the collection of products that are produced, the portfolio of capabilities that must exist in a given economy can be determined. Implications for development policy have been that countries can most easily achieve growth by diversifying into closely related industries/products and that it is hard to expand directly into less similar industries/products (Hidalgo and Hausmann, 2009). The same has been observed for regions (Kogler et al., 2013; Neffke et al., 2011; Balland et al., 2018; Daboín et al., 2019; Cicerone et al., 2020; Mealy and Coyle, 2019). For an overview over the branching out literature see Hidalgo et al. (2018).

Empirically, when the product portfolios of different countries are constructed, they often tend to follow a distinct pattern of "nestedness," in which advanced 
economies produce both common and uncommon products, while less developed economies generally produce only common products (Bustos et al., 2012). This empirical regularity deviates from that predicted by standard economic theories of trade under comparative advantage. Researchers condense the information of the full product space matrix into a one-dimensional indicator in order to be able to employ it in empirical investigations. The Economic Complexity Index (ECI; Hidalgo and Hausmann, 2009; Hausmann et al., 2013) and the Fitness Index (FI; Tacchella et al., 2012) are two such dimensionality reduction techniques.

Complexity economics has become widely used in policymaking (Balland et al., 2018; Escobari et al., 2019). Prominent examples are the government of Chile (CORFO, 2018), projects of the Harvard Growth Lab with governmental agencies of (among others) Saudi Arabia and Albania (The Growth Lab, 2020), and the inclusion of the Fitness Index in the World Bank data repository (World Bank, 2018).

\section{B. Studying Regional Economies}

There are compelling theoretical and empirical reasons to use metropolitan areas as a basic unit for studying economic geography. Metro areas capture individual commuting sheds, and are designed such that jobs within a given metro are held by residents of that metro, and vice versa. This makes them coherent in a way that municipalities (which often have large net flows of commuters in or out) and states/provinces (which may include multiple self-contained commuting sheds) are not. From a theoretical perspective, metropolitan areas are the geographic entity at which agglomeration begins (Glaeser et al., 1992; Marshall, 1890), and at which new industries are created (Jacobs, 1969). They can be functionally defined as the geographies in which face to face meetings can be undertaken without friction (Storper and Venables, 2004).

Empirically, the variation in economic performance among metros within a country is often comparable to the difference between countries, even countries at very different levels of development. For instance, the GDP per capita of the San Francisco MSA in 2017 was $\$ 90,000$ - more than four times that of the McAllen Texas MSA (U.S. Bureau of Economic Analysis, 2017). This is roughly the ratio between the GDP per capita of the United States as a whole and that of Peru (International Monetary Fund, 2017).

For these reasons, regional scientists have long sought to understand the economic performance of metropolitan regions and have used a wide swath of metrics and concepts to characterise regional economies (Isard and Reiner, 1966; Storper, 2011). Many of these, like the capabilities approach, are focused on the productive structure of metro areas, particularly on their export industries. Examples include studies of regional "economic bases" (Andrews, 1953; Heilburn, 1981), "growth poles" (Parr, 1973; Perroux, 1955), industry clusters (Porter, 1998), and industrial variety (Frenken et al., 2007). A growing literature, mostly within evolutionary economic geography, employs the capabilities approach at the regional scale (Kogler et al., 2013; Neffke et al., 2011; Daboín et al., 2019; Cicerone et al., 
2020; Mealy and Coyle, 2019; Muneepeerakul et al., 2013; Farinha et al., 2019; Essletzbichler, 2015). Like work on the productive structures of nations, these studies seek to construct the "product space" within a given country, and identify paths that subnational regions can take to develop their economies by branching into industries that are related to the ones they already have. In Europe, this relatedness approach has been used to justify regional development policies that differ from place to place depending on location within the product space (Balland et al., 2018).

In the case of the United States, recent years have provided both a normative and a positive case for focusing on regional development (Storper, 2018). Since 1980, the long-term trend of regional convergence in income levels has stalled and begun to reverse (Manduca, 2019; Amos, 2014). This divergence has led to a great deal of interest in regional economic performance in the popular media, and to calls for policymakers to treat regional economic development as a core national policy concern (Badger et al., 2016; Leonhardt, 2018).

\section{Previous Research on Regional Economic Complexity}

There have been several previous attempts to apply the lens of economic complexity to regional or subnational productive structures. These fall into two major groups. Some studies have used economic complexity measures computed from international trade data, as in the original cross-national studies, and then calculated the complexity of regions by taking dollar-weighted averages of their industry portfolios. Reynolds et al. (2018) describe the productive structure of Australia's states and find that minor differences in inter-state as well as rest-of-world exports matter greatly to relative complexity. Operti et al. (2018) apply a similar method to Brazilian states, and show that the more economically developed states are fairly stable in their levels of complexity, while the less developed states show more fluctuation over time.

The second group consists of studies that, like the present paper, calculate regional complexity using the national rather than global economic network. Gao and Zhou (2018) calculate the ECI and FI for Chinese provinces based on the number of publicly traded firms. Despite the limited coverage of this data, which they acknowledge, they corroborate cross-country findings of a positive relationship between complexity and growth. Instead of using the number of firms per sector, Chávez et al. (2017) use employment across sectors to compute the ECI of Mexican states and provide evidence that the higher a state's ECI is, the higher its GDP per capita. Davies and Maré (2019) use a continuous rather than discrete measure of industry presence for urban areas in New Zealand. They show that increases in complexity are associated with increases in employment.

In the United States, a handful of studies have calculated measures of economic complexity for subnational regions, but usually as an example of a larger theoretical point or a comparison to a preferred measure rather than an object of analytical interest in itself (Sbardella et al., 2017; Gomez-Lievano and PattersonLomba, 2019; Mealy et al., 2019, 2018). A notable exception is Balland and Rigby 
(2017) who offer one of the first measures of complexity for US metro areas, focussing specifically on the development of new technology. Using detailed patent data for US metropolitan areas between 1975 and 2010, they find that high complexity patenting tends to be geographically sticky and that the highest ranked (in terms of patent complexity) places aren't exclusively the most populous nor those with the highest income per capita.

While the papers described here represent important advances in our understanding of subnational economic complexity, they have not fully engaged with major methodological questions that emerge when translating measures developed for international exports to the subnational context, such as what types of industries should be included in complexity metrics and how to determine when an industry is present. Additionally, with the exceptions of Balland and Rigby (2017) and Davies and Maré (2019), they have typically been conducted at a coarse level of either geography or industrial classification. As we show in Appendix F.F4, many of the stylised facts underpinning complexity analysis weaken at coarse aggregation levels. Here, we build on these previous studies by using data with high resolution in terms of both space and industry category for US metropolitan areas. We begin by describing our data and addressing several major methodological questions that arise when moving from the national to the metropolitan level of analysis.

\section{Data}

We use data from the US Census County Business Patterns (CBP), an annual employment count by NAICS industry classification and county for the entire United States, for the years 1998-2015. The dataset covers approximately $84 \%$ of the Civilian Employment Level for March 2015 (U.S. Bureau of Labor Statistics, 2017).

We define industries by 6-digit NAICS code, the most disaggregated level available. In Appendix F.F4, we show that the assumptions underlying the ECI specifically tend to break down when industries are aggregated to levels coarser than 4-digit NAICS. For geographical aggregation, we use the Core Based Statistical Areas (CBSAs) as defined by the US Office of Management and Budget based on commuting flows (U.S. Census Bureau, 2012). CBSAs consist of Metropolitan Statistical Areas (MSAs) and Micropolitan Statistical Areas, and are the most common way to define metropolitan areas in the United States. We include non-core counties as individual observations in the calculation of complexity but aggregate them to one observation per state in our regressions because of computational limitations. By calculating complexity based on the complete geography of the US, we ensure that our measures are as inclusive of the employment network in the US as possible. While other geographic agglomerations are available, CBSAs are the most widely used and are based on commuting patterns. Further information on the data, the industry classification schemes and the geographic aggregation can be found in Appendix B.

An advantage of the CBP data is that they are based on employment rather 
than exports. Researchers have noted the limitations of measuring overall economic competitiveness based on exports alone, since even at a given level of development some economies may export more than others (Morrison et al., 2017). Additionally, the employment-based CBP data includes services - which account for $80 \%$ of employment in the US (BLS, 2020) - as well as goods producing industries. While some papers on economic complexity have included services in their calculations (see especially Stojkoski et al., 2016; Hausmann et al., 2013), they have been absent from most analyses.

However, no data source comes without disadvantages. A conceptual limitation of employment data is that it may underweight the presence of highly efficient industries, since they produce more output with a given level of employment. A further drawback of the NAICS industry classifications specifically is that many firms and establishments produce more than one type of product, yet they are classified in just one industry category, based on where the majority of their output is located. That said, the classification system is designed to group establishments into industries based on the similarity of their production processes (Office of Management and Budget, 2017), and only rarely do establishments produce in different industry groups (4-digit NAICS).

To see if economic complexity adds additional power to predictions of metropolitan income per capita beyond standard measures, we use a number of control variables. These can be clustered into economic controls, sociodemographic controls and institutional factors (Breau et al., 2014; Florida and Mellander, 2016). The full list of sources and further explanation for all variables employed in our analysis can be found in the Appendix A.

\section{Methodology}

This paper studies the economic complexity of US metropolitan areas. The most frequently used indicator of complexity is the Economic Complexity Index (ECI, Hidalgo and Hausmann, 2009; Hausmann et al., 2013). A second and strongly related indicator is the Fitness Index (FI, Tacchella et al., 2012). The formula and logic behind each of these indicators are described in Appendix C.

There has been a great deal of debate recently about the relative merits of the ECI and the FI (Albeaik et al., 2017a,b; Gabrielli et al., 2017; Pietronero et al., 2017). However, for regions of the United States they are extremely highly correlated. As shown in Appendix Figure F.F3, in 2015 the correlation of ECI with the log of $F I$ for US metro areas was 0.94 . Thus, it appears that the primary difference between the $E C I$ and the $F I$, at least as computed on these data, is one of scaling rather than a fundamental difference in concept. Because it produces a less skewed distribution of values and has fewer concerns about convergence (Morrison et al., 2017), we choose to focus on ECI here, though we reiterate that both measures appear to be capturing the same underlying construct with remarkable consistency, and results using the $F I$ are similar to those with the ECI. 
The Economic Complexity Index is sometimes interpreted as measuring diversity. However, it is in fact mathematically orthogonal to diversity and instead of ranking places according to their degree of diversification rather works as a dimensionality reduction algorithm which defines a distance between nodes in a graph on the basis of their similarity (Mealy et al., 2019). It does this through reciprocal averaging - what Hidalgo and Hausmann (2009) call the "method of reflections" - where a region's ECI is the average of the Product Complexity Indices $(P C I \mathrm{~s})$ of products it is specialized in.

\section{A. Applying economic complexity to metropolitan areas}

Although it was developed to study countries rather than metropolitan areas, we believe the $E C I$ is well suited to the metropolitan context. Conceptually, the $E C I$ was developed for studying systems of self-contained economic units connected by trade. That definition applies to metropolitan areas within a country just as it does to countries within the world. Empirically, as we show in Figure 1 below, industries are distributed across US metros in the same nested pattern as products often are across countries.

Nonetheless, the changed context does raise certain conceptual and empirical questions. For example, the total lack of trade barriers between regions of a country may induce regional specialisation that is due to economies of scale rather than capability limitations. There may be products that are relatively simple to produce that are nonetheless only made in few regions because a few places are sufficient to meet the demand of the whole country. This phenomenon may occur for more sophisticated industries as well. For instance, the 12 regions chosen as headquarters of Federal Reserve branches might not be the only ones endowed with the necessary capabilities for central banking, but nevertheless they suffice under the present system to supply the whole nation.

Whether this is analytically problematic is debatable: Even if other regions could easily develop the capabilities to produce simple products - or even central banks - they don't currently have them. Still, we remain alert to the general possibility, which would most likely manifest in seemingly simple industries being identified as complex because they only appear in a handful of metros.

Two further methodological questions that arise when translating economic complexity to the US metropolitan context are whether to include local industries as well as traded ones, and how to define when an industry is present in a region. We consider each of these in turn.

\section{B. The role of local industries}

Regional scientists often find it helpful to distinguish between local and traded industries. Local industries are those that meet the needs of people living in their region, while traded industries are primarily aimed at producing exports to other regions. Because most previous work on economic complexity is based on international export data, it has been limited to traded industries by necessity. We do not face this data constraint, but the question remains as to whether local industries logically fit with complexity analysis. 
The concern about including local industries in the complexity score arises because they play a fundamentally different role in the regional economy from that of traded industries. Many theorists have noted the importance of exports in bringing money into a region from the outside (Parr, 1973; Andrews, 1953). The money earned by these export industries in turn supports local industries, which form the bulk of employment (Porter, 2003; Moretti, 2010). For the purposes of measuring regional economic performance, it may thus make sense to focus only on the export industries believed to drive economic growth (c.f. Gomez-Lievano and Patterson-Lomba, 2019).

However, there are both conceptual and empirical counterarguments to this reasoning. First of all, local services can vary in complexity and ubiquity just like anything else. Consider the case of restaurants - perhaps the quintessential local service. Although restaurants exist within every metro area in the country, a big city like New York has a much wider variety of restaurants than a small town. That variety indicates a much wider range of capabilities related to food service: the capabilities to use spices from multiple ethnic cuisines, for instance, or those required to run a Michelin-starred kitchen. Importantly, these capabilities contained in local industries can still contribute to the development of new traded industries. For example, the internet meal subscription company Blue Apron was founded by combining the expertise of a chef running a local catering business with two tech industry workers (Konrad, 2015). The full economic capacities of a place can be characterised more accurately when all of its economic activity is being taken into account.

In addition, a large and diverse set of local services for consumption purposes has been proposed as a source of competitive advantage for cities: having a wide array of local restaurants, boutiques, entertainment venues, and art galleries is thought to attract members of the "creative class," with their high levels of human capital (Clark et al., 2002; Florida, 2002).

Empirically, looking at local industries collectively, it turns out that they have a similar spatial distribution to traded ones. Figure 1 shows the presence of traded, local, and all industries across metros, ordered by ubiquity and diversity, where industries are classified as local or traded according to Delgado et al. (2016). The overall nested structure documented by Bustos et al. (2012) for exports across countries is present for local, traded and all industries across US metros. We quantify this nestedness pattern using the NODF score, a measure of nestedness used in ecological studies that varies from 0 (no nestedenss) to 100 (perfect nestedness) (Almeida-Neto et al., 2008). The nestedness of industries within US metros is 49.87 for all industries together, 60.06 for local industries, and 30.77 for traded industries. This compares to a value of 70.81 in the country-product network reported by Bustos et al. (2012). Note that the nestedness pattern in our data on US CBSAs stands in contrast to the lack of nestedness found by Mealy et al. (2019) in their analysis of occupations and US states, perhaps because of the finer resolution in our data (see Appendix F.F4.) 
Given the importance of local industries and their comparable geographic distributions, we opt to use both traded and local industries in the main text. However, we also give results for complexity values calculated solely based on traded as well as solely based on local industries in Appendix F.F2. If anything, the cross section effects in the regression of income per capita on ECI are in all years stronger when only being computed based on local industries compared to ECI being only computed for traded or all industries.

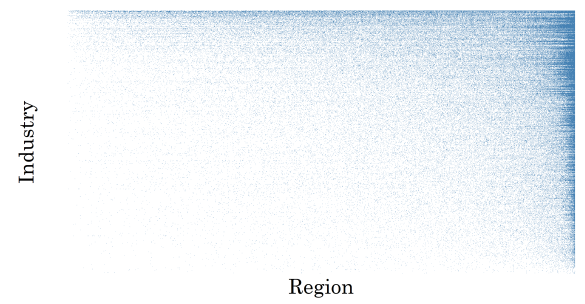

(a) Traded Industries

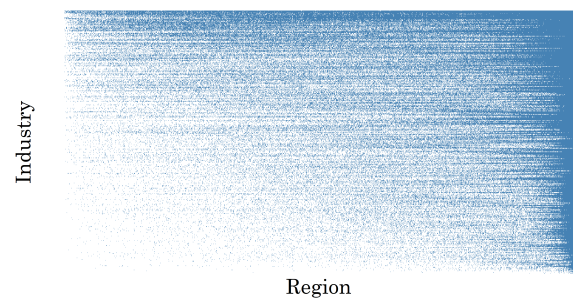

(b) Local Industries

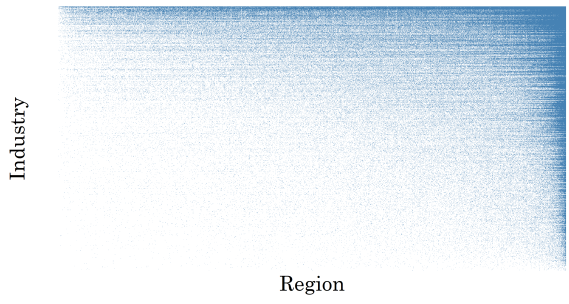

(c) All Industries

FigURE 1. INDUSTRY PRESENCE ORDERED BY UBIQUITY AND DIVERSITY: TRADED, LOCAL, AND ALL INDUSTRIES $\left(C M_{r, i}\right.$, SiX-Digit NAICS INDUSTRIES, 2015)

Source: Own calculations, Delgado et al. (2016), and CBP.

\section{The measurement of industry presence}

Economic complexity measures are constructed from a matrix of industry presence by geography. A key question is how to define when an industry is "present" in a region. Previous research has typically used a binarized version of Revealed Comparative Advantage $(R C A)$, counting a given product as present in a given country if it is over-represented in that country's basket of exports relative to its share in the rest of the world. The equivalent approach using employment data is to consider an industry present in a metro if its Location Quotient $(L Q)$ is greater than one, indicating that workers in that industry form a larger percentage of local employment than they do for the nation as a whole.

This is a reasonable starting point, but it has some weaknesses. The most notable of these is that it tends to under-report the production of common goods 
in diversified regions. Consider a country with two regions, one that produces just apples and one that produces equal quantities of apples and computers. The latter is clearly the more complex economy because it has both the capabilities that go into making apples and those that go into making computers. However, it would have a location quotient in apples of less than one, because apples form a smaller portion of its economy than they do for the nation as a whole. Arithmetically, regions with more diverse economies will tend to have location quotients below one for ubiquitous products simply because they are also producing uncommon products. We argue that this means a binarised version of the Location Quotient will under-report the presence of common industries in diverse regions.

This issue is of particular concern given the inclusion of non-traded sectors in our analysis. Previous research has documented that most local industries scale sublinearly with city size (Youn et al., 2016). This means that local industries are likely to have lower $L Q \mathrm{~s}$ in large regions, simply because of how their presence scales with population. One example of this is the case of gas stations with convenience stores (NAICS code 447110) in New York City. In 2015, the New York MSA had 13,972 employees at these gas stations, clearly an indication of the capability to provide cars with fuel. Yet, as a share of total metropolitan employment, gas stations were underrepresented in New York, with a location quotient of just 0.27. Using the standard approach of $L Q>1$, New York would be identified as lacking the capabilities involved in running gas stations. We believe that this would be an incorrect conclusion to draw.

To address this limitation, in our primary analysis we use an alternative measure of industry presence in which we consider an industry to be present in a metro if $L Q>1$ or if total employment is greater than 50. This "composite matrix" $(C M)$ allows ubiquitous industries to be correctly identified as present in diverse metro areas while still identifying the industries that smaller metros specialize in. While we believe it is an improvement on the standard $L Q$ matrix, particularly for the analysis of local industries, the $C M$ matrix does have some drawbacks. It might for example blur the differences between the most complex and medium complexity regions by inferring full capabilities in an industry from the presence of a relatively small number of workers. A full comparison of our measure with the standard $L Q>1$ measure and an alternative measure based on the presence of any employment in an industry whatsoever is provided in Appendix D. Future work in this area might also consider fully continuous alternatives to the $E C I$, such as those proposed by Davies and Maré (2019) and Gomez-Lievano and PattersonLomba (2019).

\section{Results}

A. Complexity and the Economic Geography of the United States

Figure 2 maps the economic complexity of CBSAs and non-metropolitan counties in 2015. The most complex regions are the metropolitan areas of Los Angeles, New York, Chicago, Philadelphia, and Boston. These are large cities with very diverse economies, producing all types of goods and services. The least complex 
regions tend to be rural counties, most notably those in the Great Plains. These areas' employment is centred on industries that are common in more diverse regions as well.

There are both high- and low-complexity metros in all parts of the country, including the Northeast, South, Midwest, and West. However, there is a very tight relationship between population size and economic complexity, with ECI correlated with the log of metro population size at 0.85 in 2015. This finding stands in some contrast to previous results at the country level, where many relatively small countries rank quite high. This may be because there is less overall variation in the level of economic development within the US than there is across countries, so sheer size matters more than other determinants of productive capacity. Note that this result is not driven by our approach to measuring industry presence: If we use the typical approach of $L Q>1$, instead, the correlation is 0.81. Nor is it driven by our choice to include both local and traded industries - correlations between the log of population and ECI computed with local and traded industries alone are 0.73 and 0.7 respectively. In terms of broader parts of the country, the Midwest Census Division has the lowest average complexity, followed by the South, the West, and the Northeast.

There is remarkable stability in the economic complexity of metro areas over time. The 1998 and 2015 values of ECI are correlated at 0.96 . In total, variation across time within metros accounts for just $1.7 \%$ of total variation in $E C I$ across both space and time. This suggests that there was relatively little change in the productive structures of US metros during our sample period compared to the overall variation across metros that already existed in 1998. That said, there was fluctuation in both raw and rank terms from year to year, and some CBSAs did steadily rise or fall. The Villages, Florida, for example, saw remarkable development during this period, growing from an ECI of -0.22 (rank 921 out of 978 regions) to one of 0.79 (rank 556). Moving in the other direction, Wheeling, West Virginia, saw its ECI drop from 1.27 (rank 205) in 1998 to 0.88 (rank 497) in 2015. The ranks over time are plotted in Figure E1 in Appendix E.E1. The core takeaway from the graph is that most changes occur at the middle ranks whereas the top and the bottom ranks are more consistent. 


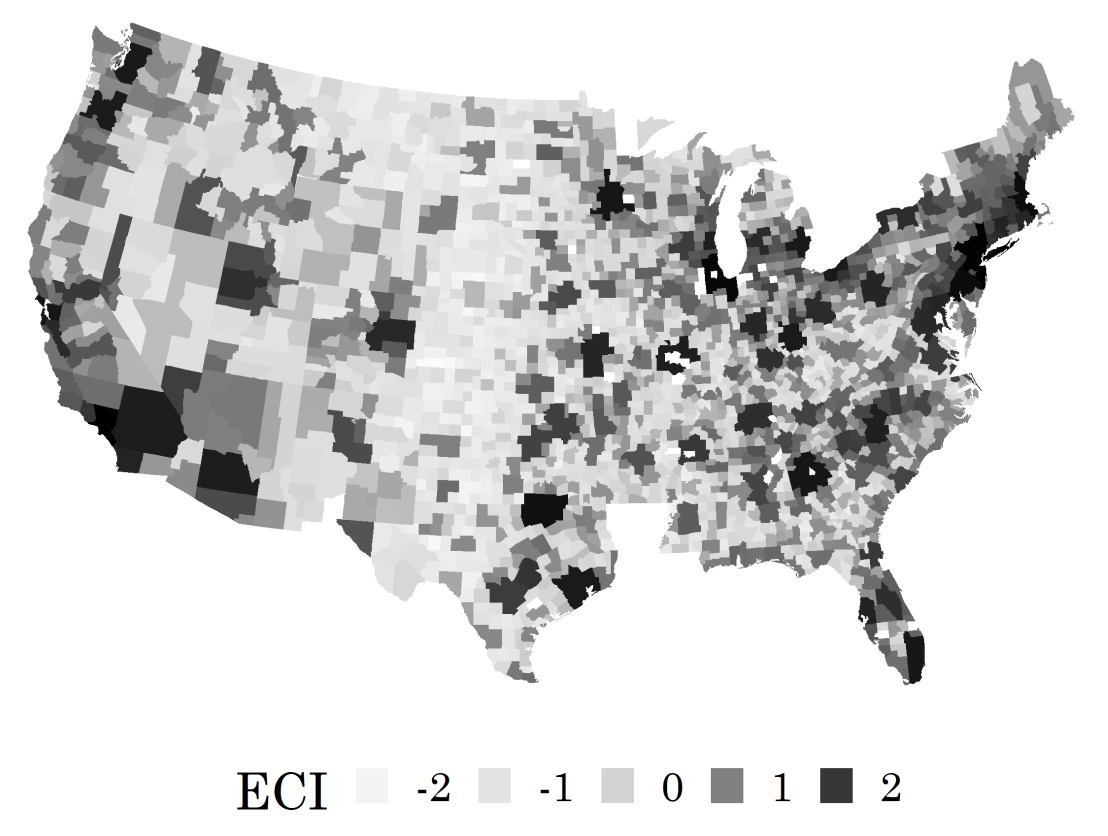

Figure 2. Map: ECI of US Core-Based Statistical Areas ( $C M_{r, i}$ Input Matrix, SiX-Digit NAICS Industries, 2015)

Source: Own calculations and CBP.

\section{B. Zooming into industries}

In Table 1, we present a list of the 10 most and least complex industries in 2015. Broadly, the most complex industries were found in finance and advanced manufacturing, while the least complex industries tended to relate to resource extraction, agriculture, and logistics. The appearance of central banking, whose geography was set by the Federal Reserve Act of 1913, highlights how the processes that determine industry presence can vary. However, we do not believe this is a weakness because - as we discussed above - only the 12 designated regions chosen as headquarters of the Federal Reserve branches have fully developed capabilities in central banking. Of the 10 highest complexity industries, only two are local. These are both subsumed under the NAICS industry group 4851 "Urban Transit Systems." This points to the underrepresentation of public transportation in many of the smaller regional units included in our analysis. Local and traded industries are roughly equally represented among the 10 least complex industries.

On average, local industries had a complexity value of -0.638 whereas traded 
TABle 1 -ICI: Highest And Lowest Complexity Industries $\left(E C I, C M_{r, i}\right.$, NAICS, 2015)

\begin{tabular}{l|l|l|c|c}
\hline & NAICS & Name & ICI & Type \\
\hline 1 & 523210 & Securities and Commodity Exchanges & 3.71 & Traded \\
2 & 521110 & Monetary Authorities-Central Bank & 3 & Traded \\
3 & 485112 & Commuter Rail Systems & 2.65 & Local \\
4 & 485119 & Other Urban Transit Systems & 2.65 & Local \\
5 & 522190 & Depository Credit Intermediation & 2.51 & Traded \\
6 & 334517 & Irradiation Apparatus Mfg. & 2.3 & Traded \\
7 & 336415 & Guided Missile and Space Vehicle Propulsion Unit $(\ldots)$ Mfg. & 2.22 & Traded \\
8 & 336414 & Guided Missile and Space Vehicle Mfg. & 2.18 & Traded \\
9 & 524130 & Reinsurance Carriers & 2.16 & Traded \\
10 & 334112 & Computer Storage Device Mfg. & 2.12 & Traded \\
11 & $\ldots$ & .. & $\ldots$ & -2.2 \\
969 & 115111 & Cotton Ginning Traded \\
970 & 447190 & Other Gasoline Stations & -2.21 \\
971 & 424910 & Farm Supplies Merchant Wholesalers & Local \\
972 & 115112 & Soil Preparation, Planting, and Cultivating & -2.21 \\
973 & 484220 & Specialized Freight (..) Trucking, Local & -2.3 & Traded \\
974 & 213111 & Drilling Oil and Gas Wells & -2.31 \\
975 & 813910 & Business Associations & -2.46 & Traded \\
976 & 424510 & Grain and Field Bean Merchant Wholesalers & -2.51 & Local \\
977 & 213112 & Support Activities for Oil and Gas Operations & -2.52 & Traded \\
978 & 211111 & Crude Petroleum and Natural Gas Extraction & -2.76 & Traded \\
\hline
\end{tabular}

ones had an average value of 0.286 (note that complexity values are normalised to have mean 0 and variance 1 , with scores above zero indicating greater than average complexity). This suggests that local industries are on the whole use less specialized capabilities than traded ones. However, 65 local industries (roughly one-fifth of the total) have higher than average complexity, including NAICS codes 561613 "Armored Car Services," 621491 "HMO Medical Centers," and "515120 Television Broadcasting." The remaining 238 local industries have lower than average complexity. In contrast, 452 of the 675 traded industries are more complex than average.

\section{The Changing Relationship between Economic Complexity and Economic} Performance

We now turn to the relationship between economic complexity and the economic performance of US metros over the years 1998-2015. We use per capita income as calculated by the Bureau of Economic Analysis as our outcome measure, and consider both the bivarate relationship between ECI and income and the relationship after controlling for a range of economic, social, and institutional factors. Before doing so, we reiterate that our investigation and regressions are not primarily aiming at a causal analysis. Rather, we want to draw a richer picture of the economic network of the US metro areas and show in which respects for example high- and low-income per capita places differ. Any further claims can only be of a very limited nature due to possible issues of endogeneity, and are complicated by our findings on the high intertemporal stability of $E C I$ over time. 
We begin by testing how higher levels of ECI are related to cross-sectional variation in regional economic outcomes. Figure 3 a shows coefficients from yearly bivariate population weighted cross-sectional regressions of logged income per capita on ECI. ECI is always a positive and highly significant predictor of crosssectional increases in income per capita. However, this relationship has noticeably weakened over time: Around the year 2007 this relationship decreased leaving the year 2015 significantly lower than the year 1998. In absolute terms: While in 1998 a one unit difference in $E C I$ between regions was associated with approximately a $17 \%$ difference in income per capita, the same difference in ECI in 2015 was only associated with a $12 \%$ difference in income per capita. Looking at the R2 (see regression table E1 in Appendix E.E2), we also see that the explanatory power decreased markedly (from $40 \%$ to $17 \%$ between 1998 to 2015 ) and the correlation between the variables fell from 0.58 to 0.33 (see Figures $3 \mathrm{c}$ and $3 \mathrm{~d}$ ).

Full regression output for the years 1998, 2007 and 2015, including results with eleven sociodemographic controls in the latter two years is presented in Appendix E.E2 (control data is not available prior to 2007, and is only observed for roughly $1 / 3$ of regions with sufficient population). The results with controls conform to the bivariate findings of an initially positive relationship that declines over time.

In 2007, controlling for our set of economic, social and institutional variables (which reduces the number of regions we have data for from 932 to 284 regions), $E C I$ has a significant coefficient of 0.07 . In 2015, this coefficient is reduced to 0.02 and has become insignificant.

\section{BEHIND THESE CHANGES}

As discussed above, metropolitan ECI levels did not change dramatically during this period, not even in the years around 2007. That means that the weakening relationship between $E C I$ and income must be a function not of changes to metropolitan productive structure but of changes to metropolitan income that were not directly tied to changes in industrial portfolio. Figure panels $3 \mathrm{c}$ and $3 \mathrm{~d}$ explore this relationship, plotting per capita income and ECI by CBSA in 1998 and 2015 respectively. The solid red lines show the fit of a quadratic regression function of per capita income on ECI.

In 1998, the relationship between $E C I$ and per capita income was generally positive across the entire spectrum, a pattern similar to the relationship found across countries. The curvature of the quadratic fit is barely visible. On average the highest-complexity metros had the highest incomes. By 2015, however, the relationship had become slightly $U$ shaped, because the low complexity regions had made bigger gains (in relative and absolute terms) in income per capita than the high complexity ones. Since metro ECI values did not change much during this period, it is the growth of incomes in low-complexity metros that appears to have altered the overall relationship.

To investigate the drivers of income growth in low-complexity metros, we explore the industry makeup of those CBSAs and non-metropolitan counties that had $E C I$ values below the mean $(\$ 40,402)$ and per capita incomes above the mean 


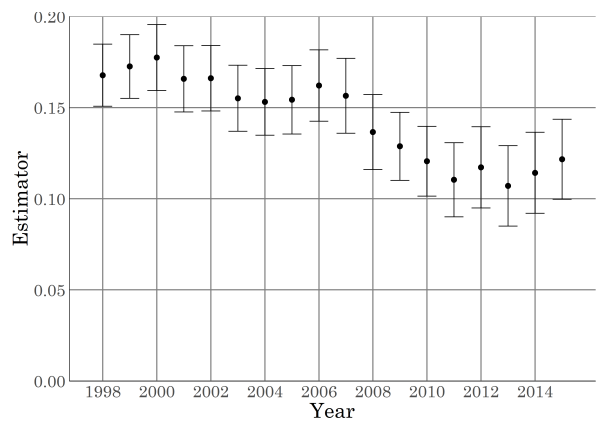

(a) Yearly bivariate cross-section regression of income per capita on $E C I\left(C M_{r, i}\right.$, NAICS)

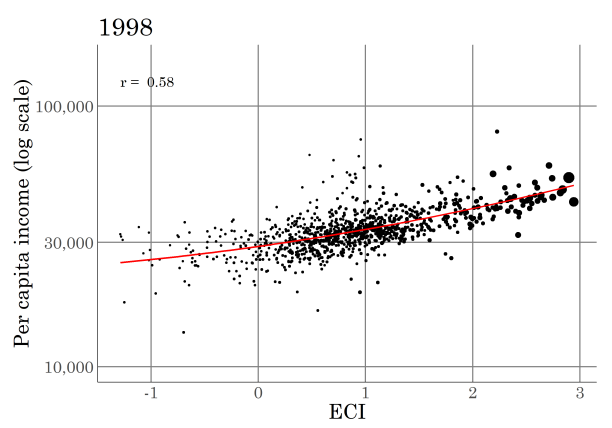

(c) Scatter Plot for 1998 Income per capita and ECI $\left(C M_{r, i}, \mathrm{NAICS}\right)$, sized by Population

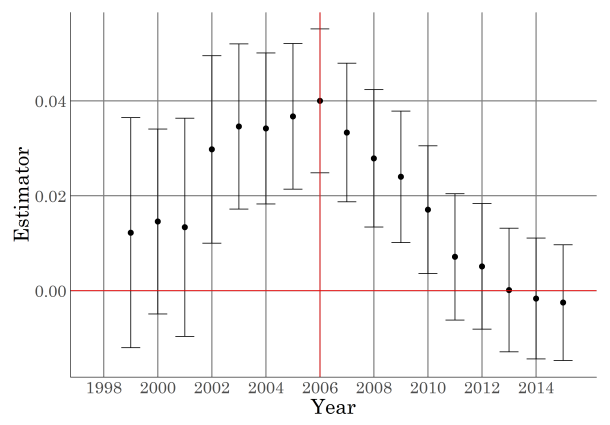

(b) Rolling fixed effects regression of income per capita on ECI adding one year at a time $\left(C M_{r, i}, \mathrm{NAICS}\right)$

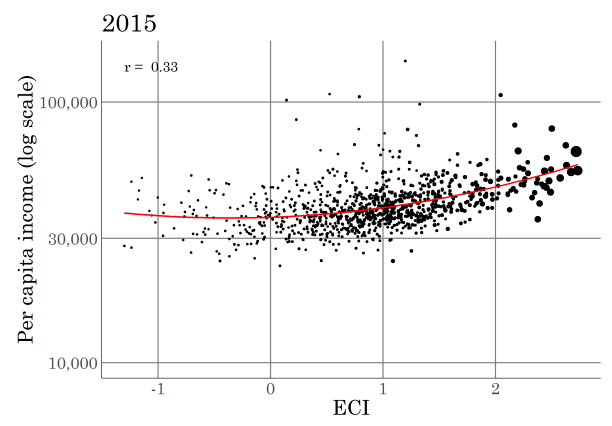

(d) Scatter Plot for 2015 Income per capita and ECI $\left(C M_{r, i}\right.$, NAICS), sized by Population

Figure 3. DiffERENT ASPECTS OF THE CHANGING RELATIONSHIP BETWEeN INCOME PER CAPITY AND ECI ( $C M_{r, i}$, NAICS $\left.)\right)$

Source: Own calculations and CBP.

in 2015. These 114 metros collectively had a population of 4.6 million in 2015 , up from 4.2 million in 1998. On average, their per capita income grew from $\$ 34,796$ in 1998 to $\$ 48,573$ in 2015 an increase of more than $\$ 13,700$ during a time where the overall national per capita income grew by just $\$ 6,837$. Over half of them are found in the states of Texas, Maine, Nebraska, South Dakota, Iowa, Kansas, Oklahoma, Wyoming.

Employment in these counties was heavily overrepresented in the mining (NAICS 21; LQ $=7.4$ ) sector. The top 10 industries in terms of LQ in those regions are entirely in mining and manufacturing, with Gold Ore Mining (NAICS 212221) and Potash, Soda, and Borate Mineral Mining (NAICS 212391) at the top.

Thus, it appears that the weakening cross-sectional relationship between metropolitan economic complexity and per capita incomes was the result of fast-growing incomes in regions whose economies were centered on resource extractiona sector that saw a global boom in the 2000s (see Jacks, 2019; Stuermer, 2018). This 
changing relationship between economic complexity and income is an important reminder that income levels are not simply an arithmetic reflection of the capacity to produce, but are contingent on a variety of macroeconomic and institutional factors. These factors can shift quite suddenly, even when productive structures do not change.

\section{Panel Regression Results}

We now turn to comparing within-metro changes in $E C I$ to within-metro changes in economic outcomes using panel regressions with robust standard errors, time fixed effects, and time-constant dummies for every region (i.e. the standard demeaning approach for two-way fixed effects regressions).

The full regression output is presented in Appendix table E2. For the whole time period, there is a non-significant, weakly negative relationship. However, when looking at the individual time period after 2007, we find that the partial effects are significantly negative. The effect is fully robust to the inclusion of our control variables (column 4). A one-unit deviation above the mean is associated with a decrease of $4 \%$ below the mean of the average region when we employ all of our controls. The converse is true for the time period before 2007: Here, ECI is a significant positive predictor. Figure $3 \mathrm{~b}$, plots the partial effect between $E C I$ and income per capita as we expand our dataset by one year at a time. It shows a similar pattern: the partial effect becomes more and more positive, peaking in 2006, and then gradually declines until becoming insignificant and negative in 2014. As with the cross sectional results, the results of panel regressions suggest a changing relationship between $E C I$ and income over time.

\section{Discussion}

Using industry employment data, this paper has applied the ideas and methods of economic complexity to the context of US regions between 1998 and 2015. After scrutinizing the underlying assumptions of complexity in a regional context, and updating the methodology where appropriate, we show that economic complexity is well suited to analysing the productive structure of US regions. Specifically, the general nested pattern of the region-industry matrix that has been observed among countries also exists in US regions. This highlights the importance of regions as a focus of economic geography.

We have also shown that the inclusion of local sectors in complexity indicators is valid and strengthens their analytic power. Local industries are an important part of regional economic life and - as we have argued - vary widely in terms of quality and sophistication. Furthermore, we described how measuring industry presence using the Location Quotient alone may underreport the industrial diversity of large and diverse regions, and introduced a new input matrix $C M_{r, i}$, which circumvents many of these problems by taking into account (almost) every industry that is present in a region. In terms of indicators, we argue that differences between ECI and $F I$ are less dramatic than they seem, at least in this context. 
Our empirical analysis revealed that the largest US cities have the highest complexity and that metropolitan areas and the Northeast of the US have a higher complexity than non-metropolitan areas and other US regions respectively. Traded industries dominate the list of most complex industries, but many local ones also have above average complexity values. In general, higher ECI regions have a significantly higher income per capita than lower ECI regions. However, this relationship has become weaker and somewhat U-shaped over time. Fixed-effects regressions suggest a marked regime change in the within-metro relationship between income and complexity: It peaked in 2007 and became negative thereafter.

The weakening relationship is not due to changes in economic complexity over time. On the contrary, metropolitan economic complexity has been remarkably stable. Rather, changes in the relationship between both variables are largely a result of changes in income per capita. Many low complexity regions saw a bigger (relative and absolute) increase in income per capita than high complexity regions did between 1998 and 2015. In the former group are regions whose economies were centered on resource extraction, suggesting that these findings may result from the commodities boom since the 2000s.

These results emphasize the need for care when studying the relationship between economic complexity - and perhaps productive structure more generally- and other socio-economic characteristics. It is likely that also regions outside of the US see a high degree of intertemporal stability in their regional specialization profile. For instance, Gao and Zhou (2018) calculate a Pearson correlation of 0.89 between the ECI of Chinese regions in 2000 and 2015, even though the Chinese economy as a whole grew much faster than the US during this period. Similarly, Chávez et al. (2017) find a correlation of 0.96 for Mexican regions for the vectors of 1998 and 2013. When the ECI exhibits such stability, attributing changes in other social indicators to changes in ECI may be misleading.

As we have shown, the capabilities approach offers a powerful perspective on local as well as national economic development. Applying it successfully requires careful attention to its underlying assumptions. But done carefully, it has a great deal to teach about the fortunes of local economies.

\section{Acknowledgement}

The authors thank Jarko Fidrmuc, Andres Gomez-Lievano, Dominik Hartmann, César Hidalgo, Penny Mealy, Emanuele Pugliese, Akira Sasahara, Angelica Sbardella, Marcel Tyrell, and participants of the North American Regional Science Conference in Vancouver for helpful comments and ideas.

\section{Disclosure Statement}

No potential conflict of interest was reported by the authors.

\section{Funding}

Robert Manduca was supported in this research by the Harvard Multidisciplinary Program in Inequality and Social Policy. Benedikt Fritz was supported in 
this research by the Cusanuswerk. 


\section{References}

Albeaik, S., Kaltenberg, M., Alsaleh, M. and Hidalgo, C. (2017a), 729 New Measures of Economic Complexity (Addendum to Improving the Economic Complexity Index).

Albeaik, S., Kaltenberg, M., Alsaleh, M. and Hidalgo, C. A. (2017b), 'Improving the Economic Complexity Index', Arixv Working Paper arXiv:1707, 1-21.

Almeida-Neto, M., Guimarães, P. R., Loyola, R. D. and Ulrich, W. (2008), 'A consistent metric for nestedness analysis in ecological systems: reconciling concept and measurement', Oikos 117(8), 1227-1239.

Amos, O. M. (2014), 'Evidence of Increasing Regional Income Variation in the United States: 1969-2006', Modern Economy 05(05), 520-532.

Andrews, R. B. (1953), 'Mechanics of the Urban Economic Base: Historical Development of the Base Concept', Land Economics 29(2), 161.

Badger, E., Bui, Q. and Pearce, A. (2016), 'The Election Highlighted a Growing Rural-Urban Split'.

Balland, P.-A., Boschma, R., Crespo, J. and Rigby, D. L. (2018), 'Smart specialization policy in the European Union: relatedness, knowledge complexity and regional diversification', Regional Studies pp. 1-17.

Balland, P.-A. and Rigby, D. L. (2017), 'The Geography of Complex Knowledge', Economic Geography 93(1), 1-23.

BLS (2020), 'Employment by major industry sector'.

Breau, S., Kogler, D. F. and Bolton, K. C. (2014), 'On the Relationship between Innovation and Wage Inequality: New Evidence from Canadian Cities', Economic Geography 90(4).

Buera, F. J. and Kaboski, J. P. (2012), 'The Rise of the Service Economy', American Economic Review 102(6), 2540-2569.

Bustos, S., Gomez, C., Hausmann, R. and Hidalgo, C. A. (2012), 'The Dynamics of Nestedness Predicts the Evolution of Industrial Ecosystems', PLoS ONE 7(11), e49393.

Chávez, J. C., Mosqueda, M. T. and Gómez-Zaldívar, M. (2017), 'Economic Complexity and Regional Growth Performance: Evidence from the Mexican Economy', The Review of Regional Studies 47(July), 201-219.

Cicerone, G., McCann, P. and Venhorst, V. A. (2020), 'Promoting regional growth and innovation: relatedness, revealed comparative advantage and the product space', Journal of Economic Geography 20(1), 293-316. 
Clark, T. N., Lloyd, R., Wong, K. K. and Jain, P. (2002), 'Amenities Drive Urban Growth', Journal of Urban Affairs 24(5), 493-515.

CORFO (2018), Informe final de Evaluación Programas Gubernamentales (EPG), Technical report.

Daboín, C., Escobari, M., Hernández, G. and Morales-Arilla, J. (2019), Economic Complexity and Technological Relatedness: Findings for American Cities.

Davies, B. and Maré, D. C. (2019), Relatedness, Complexity and Local Growth.

Delgado, M., Porter, M. E. and Stern, S. (2016), 'Defining Clusters of Related Industries', Journal of Economic Geography 16(1), 1-38.

Escobari, M., Seyal, I., Morales-Arilla, J. and Shearer, C. (2019), 'Growing Cities that Work for All', The Brookings Institution 32(26).

Essletzbichler, J. (2015), 'Relatedness, Industrial Branching and Technological Cohesion in US Metropolitan Areas', Regional Studies 49(5), 752-766.

Farinha, T., Balland, P. A., Morrison, A. and Boschma, R. (2019), 'What drives the geography of jobs in the US? Unpacking relatedness', Industry and Innovation 26(9), 988-1022.

Florida, R. (2002), The Rise of the Creative Class - Revisited, Perseus Book Group, New York.

Florida, R. and Mellander, C. (2016), 'The Geography of Inequality: Difference and Determinants of Wage and Income Inequality across US Metros', Regional Studies 50(1), 79-92.

Frenken, K., Van Oort, F. and Verburg, T. (2007), 'Related Variety, Unrelated Variety and Regional Economic Growth', Regional Studies 41(5), 685-697.

Gabrielli, A., Cristelli, M., Mazzilli, D., Tacchella, A., Zaccaria, A. and Pietronero, L. (2017), Why we like the ECI+ algorithm.

Ganong, P. and Shoag, D. (2017), 'Why Has Regional Income Convergence in the U.S. Declined?', Journal of Urban Economics 102, 79-90.

Gao, J. and Zhou, T. (2018), 'Quantifying China's Regional Economic Complexity', Physica A 492, 1591-1603.

Glaeser, E. L., Kallal, H. D., Scheinkman, J. A. and Shleifer, A. (1992), 'Growth in Cities', Journal of Political Economy 100(6), 1126-1152.

Gomez-Lievano, A. and Patterson-Lomba, O. (2019), The drivers of urban economic complexity and their connection to urban economic performance. 
Hausmann, R., Hidalgo, C., Bustos, S., Coscia, M., Simoes, A. and Yildirim, M. (2013), The Atlas of Economic Complexity: Mapping Paths to Prosperity, The MIT Pres, Cambridge, MA.

Heilburn, J. (1981), The Urban Economic Base and Economic Policy, in 'Urban Economcis and Public Policy', St. Martin's Press, New York, NY, chapter 7, pp. 153-169.

Hidalgo, C. (2015), Why Information Grows: The Evolution of Order, from Atoms to Economies, Basic Books, New York, NY.

Hidalgo, C., Balland, P.-A., Boschma, R., Delgado, M., Feldman, M. P., Frenken, K., Glaeser, E. L., He, C., Kogler, D. F., Morrison, A., Neffke, F. M. H., Rigby, D. L., Stern, S., Zheng, S. and Zhu, S. (2018), The Principle of Relatedness, in A. Morales, C. Gershenson, D. Braha, A. Minai and Y. Bar-Yam, eds, 'Unifying Themes in Complex Systems IX. ICCS 2018. Springer Proceedings in Complexity', Springer, Cham, pp. 451-457.

Hidalgo, C. and Hausmann, R. (2009), 'The Building Blocks of Economic Complexity', Proceedings of the National Academy of Sciences 106(26), 10570.

Hidalgo, C., Klinger, B., Barabási, A.-L. and Hausmann, R. (2007), 'The Product Space Conditions the Development of Nations', Science 317(5837), 482.

International Monetary Fund (2017), World Economic Database, Technical report, International Monetary Fund, Washington, D.C.

Isard, W. and Reiner, T. A. (1966), 'Regional Science: Retrospect and Prospect', Papers in Regional Science 16(1), 1-16.

Jacks, D. S. (2019), 'From boom to bust: a typology of real commodity prices in the long run', Cliometrica 13(2), 201-220.

Jacobs, J. (1969), The Economy of Cities, Vintage Press, New York, NY.

Kogler, D. F., Rigby, D. L. and Tucker, I. (2013), 'Mapping Knowledge Space and Technological Relatedness in US Cities', European Planning Studies 21(9), 1374-1391.

Konrad, A. (2015), 'Blue Apron's Got Big Plans For Dinner - But So Do Its Hungry Rivals', Forbes .

Leonhardt, D. (2018), 'America's Small-Town Crisis'.

Lyubimov, I. L., Lysyuk, M. V. and Gvozdeva., M. A. (2018), 'Atlas of economic complexity, Russian regional pages', VOPROSY ECONOMIKI 6.

Manduca, R. A. (2019), 'The Contribution of National Income Inequality to Regional Economic Divergence', Social Forces . 
Marshall, A. (1890), Principles of Economics, Macmillan and Company Limited, London.

Mealy, P. and Coyle, D. (2019), To Them That Hath: Economic Complexity and Local Industrial Strategy in the UK.

Mealy, P., Farmer, J. D. and Hausmann, R. (2018), 'Determining the Differences that Matter: Development and Divergence in US States Over 1850-2010', SSRN Electronic Journal .

Mealy, P., Farmer, J. D. and Teytelboym, A. (2019), 'Interpreting economic complexity', Science Advances 14(2), 1-9.

Moretti, E. (2010), 'Local Multipliers', American Economic Review 100(2), 373377.

Morrison, G., Buldyrev, S. V., Imbruno, M., Doria Arrieta, O. A., Rungi, A., Riccaboni, M. and Pammolli, F. (2017), 'On Economic Complexity and the Fitness of Nations', Scientific Reports 7(1), 15332.

Muneepeerakul, R., Lobo, J., Shutters, S. T., Gomez-Lievano, A. and Qubbaj, M. R. (2013), 'Urban Economies and Occupation Space: Can They Get "There" from "Here"?', PLoS ONE 8(9), 1-8.

Neffke, F. (2009), Productive places: The influence of technological change and relatedness on agglomeration externalities, $\mathrm{PhD}$ thesis.

Neffke, F. M. H., Henning, M. and Boschma, R. (2011), 'How Do Regions Diversify over Time? Industry Relatedness and the Development of New Growth Paths in Regions', Economic Geography 87(3), 237-265.

Office of Management and Budget (2017), North American industry classification system : United States, 2017, United States. Executive Office of the, President, Lanham, MD : Springfield, VA.

Operti, F. G., Pugliese, E., Andrade, J. S., Pietronero, L. and Gabrielli, A. (2018), 'Dynamics in the Fitness-Income plane: Brazilian states vs World countries', PLOS ONE 13(6), e0197616.

Parr, J. B. (1973), 'Growth Poles, Regional Development, and Central Place Theory', Papers in Regional Science 31(1), 173-212.

Perroux, F. (1955), 'Note sur la notion de poles croissance', Economic Appliquee 1\&2, $307-320$.

Pietronero, L., Cristelli, M., Gabrielli, A., Mazzilli, D., Pugliese, E., Tacchella, A. and Zaccaria, A. (2017), Economic Complexity: "Buttarla in caciara" vs a constructive approach. 
Porter, M. E. (1998), 'Clusters and the New Economies of Competition', Harvard Business Review p. 77.

Porter, M. E. (2003), 'The Economic Performance of Regions', Regional Studies 37(6-7), 549-578.

Reynolds, C., Agrawal, M., Lee, I., Zhan, C., Li, J., Taylor, P., Mares, T., Morison, J., Angelakis, N. and Roos, G. (2018), 'A Sub-National Economic Complexity Analysis of Australias States and Territories', Regional Studies 52(5), 715-726.

Sbardella, A., Pugliese, E. and Pietronero, L. (2017), 'Economic development and wage inequality: A complex system analysis', PLOS ONE 12(9), 1-26.

Stojkoski, V., Utkovski, Z. and Kocarev, L. (2016), 'The Impact of Services on Economic Complexity: Service Sophistication as Route for Economic Growth', PLoS ONE 11(8), e0161633.

Storper, M. (1997), The Regional World: Territorial Development in a Global Economy, Guilford Press.

Storper, M. (2011), 'Why do Regions Develop and Change? The Challenge for Geography and Economics', Journal of Economic Geography 11(2), 333-346.

Storper, M. (2018), 'Separate Worlds? Explaining the Current Wave of Regional Economic Polarization', Journal of Economic Geography 18(2), 247-270.

Storper, M. and Venables, A. J. (2004), 'Buzz: Face-to-Face Contact and the Urban Economy', Journal of Economic Geography 4(4), 351-370.

Stuermer, M. (2018), '150 years of boom and bust: what drives mineral commodity prices?', Macroeconomic Dynamics 22(3), 702-717.

Tacchella, A., Cristelli, M., Caldarelli, G., Gabrielli, A. and Pietronero, L. (2012), 'A New Metrics for Countries' Fitness and Products' Complexity', Scientific Reports 2.

The Growth Lab (2020), 'Projects Harvard Growth Lab'.

U.S. Bureau of Economic Analysis (2017), Regional Economic Accounts, Technical report, U.S. Bureau of Economic Analysis.

U.S. Bureau of Labor Statistics (2017), 'Civilian Employment Level'.

U.S. Census Bureau (2012), '2010 Census Summary File Technical Documentation/prepared by the U.S. Census Bureau'.

World Bank (2018), 'Economic Fitness Data'.

Youn, H., Bettencourt, L. M. A., Lobo, J., Strumsky, D., Samaniego, H. and West, G. B. (2016), 'Scaling and Universality in Urban Economic Diversification', Journal of the Royal Society, Interface 13(114), 1-7. 
Appendix A. Data Sources

Table A1—: Data and Data Sources

\begin{tabular}{|c|c|c|c|}
\hline $\begin{array}{l}\text { Variable } \\
\text { Names }\end{array}$ & Description & Source & $\begin{array}{l}\text { Additional } \\
\text { Information }\end{array}$ \\
\hline \multicolumn{4}{|c|}{ Dependent Variables } \\
\hline $\begin{array}{ll}\text { INCOME } & \text { PER } \\
\text { CAPITA } & \end{array}$ & Income per Capita & $\begin{array}{lrl}\text { BEA } & \text { Regional } & \text { Eco- } \\
\text { nomic } & \text { Accounts }\end{array}$ & \\
\hline \multicolumn{4}{|c|}{ Measures of Productive Structures } \\
\hline ECI & $\begin{array}{l}\text { Economic Complexity Index calcu- } \\
\text { lated either based on NAICS or } \\
\text { BCD. For both on } 6 \text { digit level }\end{array}$ & $\begin{array}{l}\text { County Business Pat- } \\
\text { terns }\end{array}$ & \\
\hline FI & $\begin{array}{l}\text { Fitness Index calculated either } \\
\text { based on NAICS or BCD. For both } \\
\text { on } 6 \text { digit level }\end{array}$ & $\begin{array}{l}\text { County Business Pat- } \\
\text { terns }\end{array}$ & \\
\hline \multicolumn{4}{|c|}{ Economic Controls } \\
\hline $\begin{array}{l}\text { UNEMPLOY- } \\
\text { MENT }\end{array}$ & $\begin{array}{l}\text { Unemployment as a percentage of } \\
\text { the total working population }\end{array}$ & $\begin{array}{l}\text { American Community } \\
\text { Survey }\end{array}$ & \\
\hline MANUSHARE & $\begin{array}{l}\text { Share of the employed population } \\
\text { working in manufacturing sector }\end{array}$ & $\begin{array}{l}\text { County Business Pat- } \\
\text { terns }\end{array}$ & \\
\hline PATENT & Number of patents filed per year & $\begin{array}{l}\text { U.S. Patent and Trade- } \\
\text { mark Office }\end{array}$ & \\
\hline \multicolumn{4}{|c|}{ Sociodemographic Controls } \\
\hline MEDiAnAGE & $\begin{array}{l}\text { Median age of the population liv- } \\
\text { ing in the region }\end{array}$ & $\begin{array}{l}\text { American Community } \\
\text { Survey }\end{array}$ & \\
\hline POPUlation & Number of people living in a region & $\begin{array}{l}\text { BEA Regional Eco- } \\
\text { nomic }\end{array}$ & \\
\hline EDUCATION & $\begin{array}{l}\text { Share of people older than } 18 \text { with } \\
\text { more than a high school degree }\end{array}$ & $\begin{array}{l}\text { American Community } \\
\text { Survey }\end{array}$ & \\
\hline BlaCK SHARE & $\begin{array}{l}\text { Share of the population identifying } \\
\text { as being of African American ori- } \\
\text { gin (alone or in combination with } \\
\text { other races) }\end{array}$ & $\begin{array}{l}\text { American Community } \\
\text { Survey }\end{array}$ & \\
\hline FOREIGN & $\begin{array}{l}\text { Share of foreign born people in the } \\
\text { total population }\end{array}$ & $\begin{array}{l}\text { American Community } \\
\text { Survey }\end{array}$ & \\
\hline \multicolumn{4}{|c|}{ Institutional Controls } \\
\hline $\begin{array}{l}\text { UNION COVER- } \\
\text { AGE }\end{array}$ & $\begin{array}{l}\text { Union coverage at the state level in } \\
\text { which the region is mainly situated }\end{array}$ & unionstats.com & $\begin{array}{l}\text { Only available at the } \\
\text { State level. }\end{array}$ \\
\hline $\begin{array}{l}\text { Minimum } \\
\text { WaGE }\end{array}$ & $\begin{array}{l}\text { Minimum Wage at the state level } \\
\text { in which the region is situated. }\end{array}$ & $\begin{array}{l}\text { Department of Labor, } \\
\text { State Minimum Wage } \\
\text { Rate (via FRED) }\end{array}$ & $\begin{array}{l}\text { On the State level as } \\
\text { only in recent years } \\
\text { few cities have intro- } \\
\text { duced their own min- } \\
\text { imum wages }\end{array}$ \\
\hline Vote & $\begin{array}{l}\text { Eligible voting population voter } \\
\text { turnout on November elections in } \\
\text { even years }\end{array}$ & electproject.org & $\begin{array}{l}\text { The votes from even } \\
\text { years are duplicated } \\
\text { for the odd years (no } \\
\text { November elections) } \\
\text { - Always the votes for } \\
\text { the highest office (in } \\
\text { presidential election } \\
\text { years the presidential } \\
\text { vote, in other years } \\
\text { either governor, sen- } \\
\text { ator or congressional } \\
\text { vote) }\end{array}$ \\
\hline
\end{tabular}




\section{Appendix B. Further Information on the Data \\ B1. County Business Patterns}

The CBP dataset provides employment counts by NAICS industry classification and county for the entire United States. It is constructed from the Business Register, a Census database of all known single and multi-establishment companies in the United States, and created through a combination of surveys and administrative records (U.S. Bureau of Labor Statistics, 2017). Data are released annually with estimates of employment during the week of March 12 of each year. The CBP data cover most economic activity in the United States, with the exceptions of crop and animal production, rail transportation, certain types of financial funds, self-employed individuals, and most government activity.

The CBP data provide counts of total employment by county and NAICS industry code. Observations are suppressed if there are too few employers within a given county-industry cell to maintain anonymity. These observations are assigned to one of twelve categories based on the total employment size. We replace these observations with the midpoint of the identified size range. In total, for 2015 we directly observe employment counts for approximately 99 million employees, and impute employment based on size code for 26 million more. This gives us a total dataset covering approximately 125 million employees, approximately $84 \%$ of the Civilian Employment Level for March 2015 (U.S. Bureau of Labor Statistics, 2017). We use CBP data for the years 1998-2015 for our measures of economic complexity.

\section{B2. Industry Classification Scheme}

An important decision when analysing productive structure is which industry classification scheme and level of aggregation to use.

The CBP data use the NAICS classification scheme for employment, which ranges in aggregation from the two-digit level (sectoral level, 19 categories) to the six-digit level (national industry level, 977 categories). To investigate the consequences of aggregation level for our complexity calculations, we conduct the analysis using levels of aggregation from two- to six-digit, as reported in Appendix F.F4. A correlation plot shows that regional ECI values are strongly correlated at the five- and six-digit level, but much less so at aggregation levels lower than five- and especially four-digits. . Based on this analysis and to maximize the information value, we use the most disaggregated NAICS level in our primary analysis.

\section{B3. Geographic Aggregation}

A second important question is how to define geographic regions. We use Core Based Statistical Areas (CBSAs). CBSAs consist of Metropolitan (MSA) and Micropolitan ( $\mu \mathrm{SA})$ Statistical Areas, and have at least one urbanised area at their core (>50,000 people for MSA, 10,000-50,000 for $\mu \mathrm{SA}$ ), to which neighbouring counties are tied based on their "degree of social and economic integration with the central county or counties as measured by commuting ties" (U.S. Census 
Bureau, 2012). For the purposes of calculating economic complexity measures, we include non-metropolitan counties as individual units, since these counties are deemed to be economically independent. Because of computing limitations, we aggregate non-core counties into one observation per state for our regression analysis. We have full control data for regions which cover roughly $65 \%$ of the US population (210 million inhabitants).

\section{Appendix $C$. Logic and Formulae of Economic Complexity}

The goal of economic complexity measures is to condense the information contained in the industrial portfolios of a set of economies (countries in the original work; metropolitan areas in this case) into a single statistic that summarises the extent of the capabilities found in each economy.

The starting point is a matrix of industry presence by region. For the $E C I$ and FI indicators, which we use here, this matrix is binary:

$$
\begin{aligned}
& M_{r, i}=1 \text { if industry } \mathrm{i} \text { is present in region } \mathrm{r}, \text { and } \\
& M_{r, i}=0 \text { otherwise }
\end{aligned}
$$

In most previous implementations, an industry is defined as being "present in a region if its Location Quotient (LQ), the ratio of that industrys fraction of regional employment to its fraction of national employment, is greater than 1 . However, as described in section IV.C of the main text and Appendix D below, our preferred specification uses a composite measure of industry presence in which an industry is defined as being present if $L Q>1$ or if total employment in the region is over 50. Once a presence matrix $M_{r, i}$ is chosen, the Diversity of any region can be calculated as:

$$
\text { Diversity }_{r}=k_{r, 0}=\sum_{i=1}^{n} M_{r, i}
$$

where $n$ is the total number of industries. And accordingly, the ubiquity of an industry is defined as the number of regional units it has is present in:

$$
\text { Ubiquity }_{i}=k_{i, 0}=\sum_{r=1}^{m} M_{r, i}
$$

where $m$ is the number of regions. Because some industries may be uncommon not because they combine many capabilities but because they utilize rare inputs (such as certain natural resources only found in a small number of places), Hidalgo and Hausmann (2009) introduce the "Method of Reflections" in which a region's diversity is adjusted for the average ubiquity of its products and vice versa. This can be implemented iteratively, with the $N^{t h}$ iteration calculated as: 


$$
\begin{aligned}
k_{r, N} & =\sum_{r^{\prime}} k_{r^{\prime}, N-2} \sum \frac{M_{r, i} M_{r^{\prime}, i}}{k_{r, 0} k_{i, 0}}=\sum_{r^{\prime}} \tilde{M}_{r r^{\prime}} k_{r^{\prime}, N-2} \\
\text { with } M_{r r^{\prime}} & =\sum_{r} \frac{M_{r, i} M_{r^{\prime}, i}}{k_{r, 0} k_{i, 0}}
\end{aligned}
$$

The ECI is thereby defined as:

$$
E C I=\frac{K_{r}-\left\langle K_{r}\right\rangle}{\operatorname{std}\left(K_{r}\right)}
$$

where $K_{r}$ is the second largest eigenvector (the largest eigenvector is just a vector of $1 \mathrm{~s}$ ) of the presence matrix $M_{r, i}$ and $\left\langle K_{r}\right\rangle$ is the mean of the respective eigenvector.

The $F I$ is closely related to the $E C I$ but differs in a few relevant aspects. The first step, constructing the presence matrix $M_{r, i}$ and determining diversity and ubiquity, is exactly the same as for ECI. In the second step, again the ubiquity of industries and diversity of regions are iteratively used to correct each other, such that an industry is labeled more complex if it tends to be found in more complex regions, and vice versa. But unlike the ECI, the FI corrects the complexity of industries using the complexity of the least complex region in which they are present, rather than the average This results in the following set of non-linear equations:

$$
\left\{\begin{array} { l } 
{ \tilde { F } _ { r } ^ { ( n ) } = \sum _ { i } M _ { r , i } Q _ { i } ^ { n - 1 } } \\
{ \tilde { Q } _ { i } ^ { ( n ) } = \frac { 1 } { \sum _ { r } M _ { r , i } \frac { 1 } { F _ { C } ^ { n - 1 } } } }
\end{array} \rightarrow \left\{\begin{array}{l}
F_{r}^{(n)}=\frac{\tilde{F}_{r}^{(n)}}{\left\langle\tilde{F}_{r}^{(n)}\right\rangle_{r}} \\
Q_{i}^{(n)}=\frac{\tilde{Q}_{i}^{(n)}}{\left\langle\tilde{Q}_{i}^{(n)}\right\rangle_{i}}
\end{array}\right.\right.
$$

where $F_{r}^{(n)}$ is the fitness of a regional unit (proportional to the sum of industries weighted by their complexity $Q_{i}^{(n)}$ ) and $Q_{i}^{(n)}$ is the industry complexity (the inverse proportional to the number of regional units possessing it corrected/weighted by the fitness of the regional units; the higher the fitness the smaller the weight) being normalized in each new step. Note that unlike the ECI, in which the limit of the interative process can be computed directly as the second eigenvector of the presence matrix, the FI must be constructed iteratively. Here we calculate the FI using 500 iterations. 
Appendix D. Construction and Comparison of the Different Input Matrices D1. How to measure industry presence

As described above, the starting point for the $E C I$ is a matrix $M_{r, i}$ of industry presence by region. In cross-national studies, the typical approach has been to identify country $r$ as producing product $i$ if $R C A_{r, i}>1$ - that is, if the product occupies a greater portion of their export basket than that of the average country. In the subnational context, the computational equivalent of $R C A$ is the Location Quotient $(L Q)$, which measures an industry's employment share in a particular region as a fraction of its employment share in the nation as a whole. Let $X_{r, i}$ denote the number of employees in region $r$ who are employed in industry $i$. Then

$$
L Q_{r, i}=\frac{X_{r, i}}{\sum_{i} X_{r, i}} / \frac{\sum_{r} X_{r, i}}{\sum_{r, i} X_{r, i}}
$$

The traditional matrix of industry presence, which we denote as the binarized LQ matrix $B M_{r, i}$, is constructed as:

$$
\begin{array}{lll}
B M_{r, i}=1 & \text { if } & L Q_{r, i} \geq 1 \\
B M_{r, i}=0 & \text { if } & L Q_{r, i}<1
\end{array}
$$

As discussed in Section IV.C of the main text, the binarised LQ matrix has certain weaknesses, most notably that it is prone to undercounting ubiquitous industries in diverse regions and local industries in large cities.

To address this weakness, we consider two alternative measures of industry presence. The first, which we term the Presence matrix $P M_{r, i}$, is based on the presence of any employment in an industry whatsoever. That is, if an industry is represented at all in a region, we assign it a value of 1 , and we only give it a value of 0 if not a single worker in the region works in the industry:

$$
\begin{array}{lll}
P M_{r, i}=1 & \text { if } & X_{r, i} \geq 1 \\
P M_{r, i}=0 & \text { if } & X_{r, i}=0
\end{array}
$$

The second alternative, the combined matrix $\left(C M_{r, i}\right)$, is a compromise between the binarised location quotient matrix $B M_{r, i}$ and the presence matrix $P M_{r, i}$. It counts an industry as "present" in a region if its location quotient is over 1 or if it employs more than 50 people in that region. Thereby, $C M_{r, i}$ corrects for artificially low location quotients in large or diverse regions. In the gas station example in the main text, New York has $C M_{r, i}=1$ because its total employment at gas stations is well over 50 , even though $L Q<1$. At the same time, small regions will still be identified as specialising in an industry if the respective location quotient is greater than one, even if the absolute number of employees is small. Mathematically, $C M_{r, i}$ can be written as follows: 


$$
C M_{r, i}=1 \quad \text { if } \quad L Q_{r, i} \geq 1 \quad \text { or } \quad X_{r, i}>50
$$

Both $P M_{r, i}$ and $C M_{r, i}$ avoid the problems of sublinear scaling and undercounting in diverse regions because (nearly) all employment counts towards their complexity score. However, one might argue that both blur the differences between the most complex and medium complexity regions by inferring full capabilities for an industry from the presence of a potentially small number of workers.

Both matrices also have individual disadvantages. The cut-off value of $C M_{r, i}$ is to some degree arbitrary: Why not use a cut-off of 100 workers or 200 or 1000? Surely cut-offs could differ across regions with different population sizes. Therefore, $C M_{r, i}$ might neglect the importance of smaller region's specialisations. $P M_{r, i}$, on the other hand, may be too sensitive to industries with small levels of employment in a region. The extent of a region's capabilities in an industry is perhaps questionable when less then a dozen of people work in it. Moreover, in some cases there might be actually no employment at all in an industry that is recorded as having fewer than 19 employees due to the way we impute employment from size codes (see Appendix B).

Furthermore, we might expect that $E C I$ based on $P M_{r, i}$ is simply a measure of population: The larger the region, the higher the chance that it has at least minimal presence in all industries. Indeed, research by Youn et al. (2016) has shown that industry diversity increases linearly with the logarithm of population and reaches a point of saturation at higher population levels. However, Youn et al. (2016) argue that this saturation is the result of finite industry resolution and the failure to capture industrial diversity rather then an actual saturation above a certain population level. In any case, measures of complexity computed from $P M_{r, i}$ would most likely fail to add any meaningful explanatory power to regressions of income where population as an independent variable is included.

To inform our choice of input matrix, we conduct an empirical investigation of the patterns of nestedness found in each matrix and the correlation patterns of $E C I$ computed from each matrix with one another and with population.

\section{D2. Comparing the Input Matrices}

In Fig D1, we show the graphical representation of industry location across regions (using CBSAs) and industries (using NAICS), where regions are ordered from left to right by diversity and industries are sorted from bottom to top by ubiquity. The three different graphs correspond to the three different input matrices discussed above.

The plots of $B M_{r, i}, P M_{r, i}$, and $C M_{r, i}$ all reveal a nested structure similar to those observed for the product exports of countries (Bustos et al., 2012). The most uncommon industries are disproportionately found in the most diverse regions, while regions with low diversity tend to have ubiquitous industries. This can be seen in the triangular structure of the three images. 


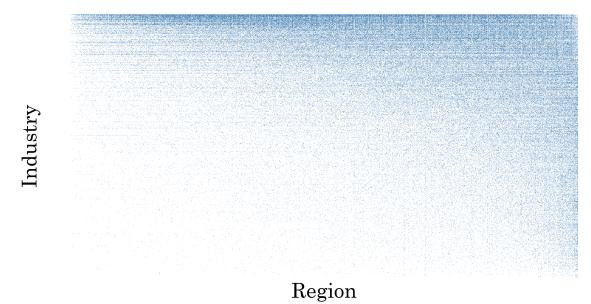

(a) $B M_{r, i}$

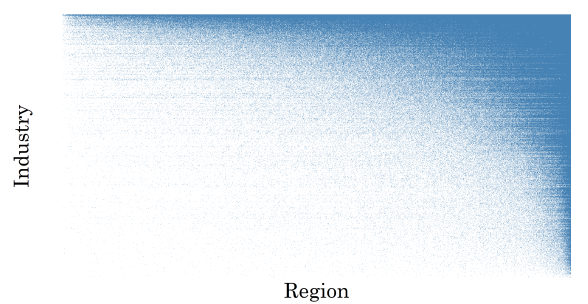

(b) $P M_{r, i}$

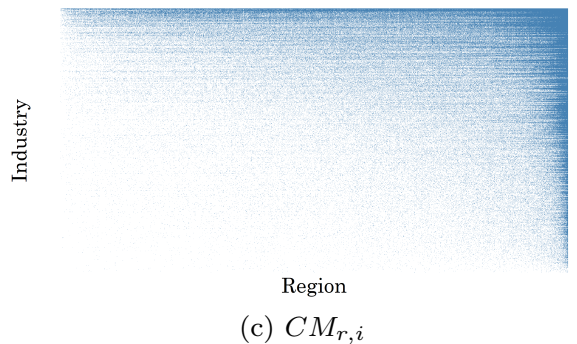

Figure D1. Candidate input matrices ordered by Ubiquity and DiVERSity (SIX-Digit NAICS INDUSTRIES, 2015)

Source: Own calculations and CBP.

Visually, the triangular nested structure appears strongest for $P M_{r, i}$, followed by $C M_{r, i}$ and then $B M_{r, i}$. To quantify that observation, we use the NODF metric developed by Almeida-Neto et al. (2008) to measure nestedness in ecological systems.

Applied to an industry-region matrix, the NODF quantifies independently whether (1) regions with few industries can be subsumed under the structure of progressively more diverse ones and (2) whether less frequent industries are found in the regions where the most widespread occur. Higher NODF values indicate a more nested structure where high diversity regions are more likely to have uncommon industries.

Table D1 shows that $P M_{r, i}$ has the highest NODF values, meaning that these input matrices show the strongest nesting patterns and - computationally - are the most nested. $B M_{r, i}$ has the lowest and $C M_{r, i}$ the second lowest value. It is somewhat surprising to see the traditional input matrix having the least nested form. Note, however, that the correlation between the $E C I$ values calculated from the different input matrices is quite high, with pairwise values between 0.966 and 0.990. Interestingly, the correlations for $F I$ are somewhat lower (between 0.841 and 0.941).

A major concern about the $P M_{r, i}$ matrix is that it might simply be a proxy for population. To determine this, we calculate the correlation between log of population and ECI computed with each of the three candidate input matrices. 
TABle D1-NODF VAlues

\begin{tabular}{lcc}
\hline \hline$C M_{r, i}$ & Presence $_{r, i}$ & $B M_{r, i}$ \\
49.87 & 73.60 & 35.75 \\
\hline
\end{tabular}

The correlation plot in Figure D.D2 shows that the $E C I$ based on $P M_{r, i}$ is indeed strongly correlated with log population (0.94). The strong correlation only peters out at the highest population levels (in line with the findings of Youn et al. 2016). $E C I$ based on $C M_{r, i}$ is correlated with log population at 0.87 , while $E C I$ based on $B M_{r, i}$ is correlated at 0.83 This finding might suggest that Presence $_{r, i}$ is too strongly correlated with population to be seen as a separate explanatory variable while differences between $C M_{r, i}$ and $B M_{r, i}$ are negligible in this respect.

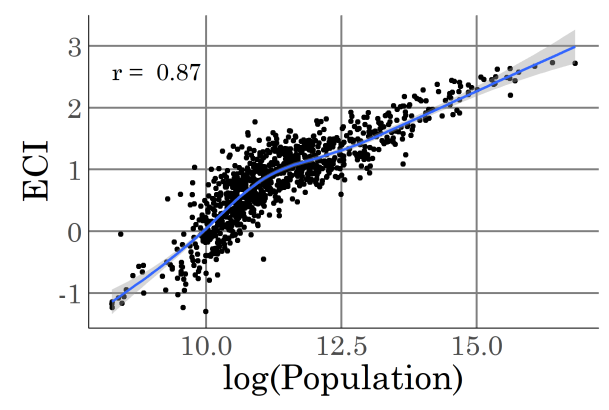

(a) $C M_{r, i}$

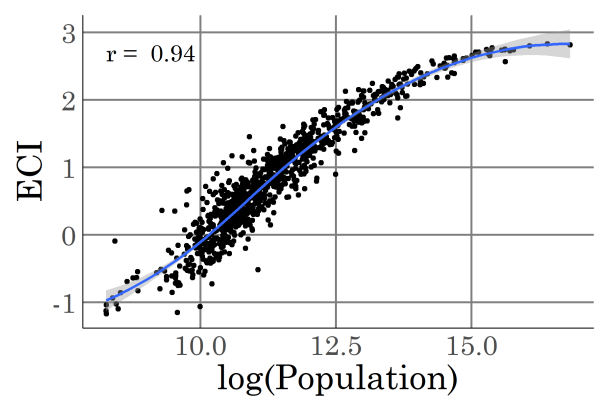

(b) $P M_{r, i}$

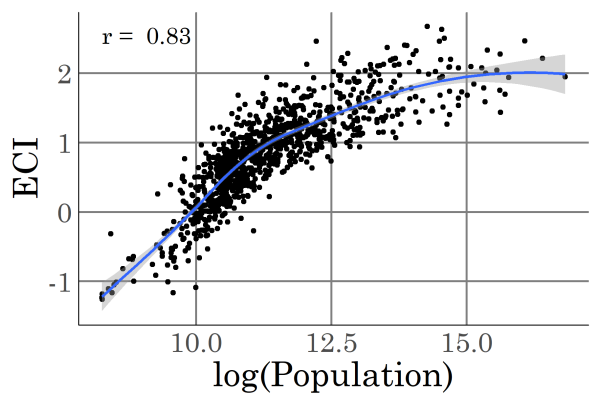

(c) $B M_{r, i}$

Figure D2. Scatter Plots of Log Population va ECI Calculated from Each Candidate Input Matrix (SiX-Digit NAICS Industries, 2015) 


\section{Appendix E. AdDitional Main Results}

\section{E1. ECI rankings}

Figure E1 plots the ECI rank from 1998-2015 for each of the 312 regions for which we observe control variables. Each line represents one region, with colours corresponding to the ranking in 2015. Rankings at the top tend to be stable over time, while there is more fluctuation in ranks below 100 (which correspond roughly to the middle portions of the 978 regions in our analysis).

\section{E2. Full Regression Output}

Here we provide the full regression output from the analysis shown in Figure $3 \mathrm{a}$ and $3 \mathrm{~b}$. Table E1 shows the results of cross sectional regression of per capita income on $E C I$ for the years 1998, 2007, and 2015. For the latter two years, we include results both with and without sociodeomgraphic controls. Many of our control variables are not observed prior to 2007, so we do not shown controlled results for 1998. In all three years there is a positive relationship between ECI and income per capital, though the relationship weakens after 2007 and is not statistically significant in 2015 once controls are included.

Table E2 shows the results of panel regressions comparing within-region changes in $E C I$ over time to changes in per capita income. All panel regressions have two way fixed effects for region and year. Because control variables are not available for our entire sample period, we focus primarily on the analysis without control variables. Column 1 shows results for the full period, while Column 2 shows those for the years 1998-2006 only and Column 3 shows 2007-2015 only. The coefficients shown in Figure 3b of the main text are from the analogous panel regressions adding one year at a time (i.e., the coefficient from Column 2 is shown in Figure $3 \mathrm{~b}$ under the year 2006, and the coefficient from Column 1 is shown under the year 2015). Column 4 shows results for the period 2007-2015 when controls are included.

The within-region relationship between $E C I$ and per capita income changed over the course of our sample period. Prior to 2006, it was significant and positive: increases in ECI were associated with increases in per capita income. But in the period since 2007 the opposite has been true: decreases in ECI have been associated with increases in per capita income. Possible drivers of this change are discussed in the main text. 
Table E1-Cross-Section Regression: log(Income Per Capita) (NAICS, $\left.C M_{r, i}, \mathrm{ECI}\right)$

\begin{tabular}{|c|c|c|c|c|c|}
\hline & \multicolumn{5}{|c|}{ Dependent variable: } \\
\hline & \multicolumn{5}{|c|}{ Per capita income (log scale) } \\
\hline & 1998 & \multicolumn{2}{|c|}{2007} & \multicolumn{2}{|c|}{2015} \\
\hline & $(1)$ & $(2)$ & $(3)$ & $(4)$ & $(5)$ \\
\hline ECI & $\begin{array}{c}0.168^{* * *} \\
(0.007)\end{array}$ & $\begin{array}{c}0.156^{* * *} \\
(0.008)\end{array}$ & $\begin{array}{l}0.074^{*} \\
(0.042)\end{array}$ & $\begin{array}{c}0.122^{* * *} \\
(0.009)\end{array}$ & $\begin{array}{c}0.023 \\
(0.047)\end{array}$ \\
\hline Unemployment & & & $\begin{array}{c}-0.021^{* * *} \\
(0.005)\end{array}$ & & $\begin{array}{c}-0.020^{* * *} \\
(0.005)\end{array}$ \\
\hline ManuShare & & & $\begin{array}{c}-0.240^{*} \\
(0.143)\end{array}$ & & $\begin{array}{l}-0.246 \\
(0.155)\end{array}$ \\
\hline $\log ($ Patent $)$ & & & $\begin{array}{c}0.016 \\
(0.010)\end{array}$ & & $\begin{array}{c}0.041^{* * *} \\
(0.012)\end{array}$ \\
\hline Population & & & $\begin{array}{l}-0.028 \\
(0.023)\end{array}$ & & $\begin{array}{c}-0.047^{* *} \\
(0.023)\end{array}$ \\
\hline MedianAge & & & $\begin{array}{c}0.017^{* * * *} \\
(0.002)\end{array}$ & & $\begin{array}{c}0.008^{* * *} \\
(0.002)\end{array}$ \\
\hline Education & & & $\begin{array}{c}0.009^{* * *} \\
(0.002)\end{array}$ & & $\begin{array}{c}0.006^{* * *} \\
(0.002)\end{array}$ \\
\hline BlackShare & & & $\begin{array}{c}0.004^{* * *} \\
(0.001)\end{array}$ & & $\begin{array}{c}0.003^{* * *} \\
(0.001)\end{array}$ \\
\hline Foreign & & & $\begin{array}{c}0.008^{* * *} \\
(0.001)\end{array}$ & & $\begin{array}{c}0.008^{* * *} \\
(0.002)\end{array}$ \\
\hline UnionCoverage & & & $\begin{array}{c}0.002 \\
(0.002)\end{array}$ & & $\begin{array}{c}0.006^{* *} \\
(0.002)\end{array}$ \\
\hline MinimumWage & & & $\begin{array}{c}0.001 \\
(0.014)\end{array}$ & & $\begin{array}{l}-0.007 \\
(0.015)\end{array}$ \\
\hline Vote & & & $\begin{array}{l}0.003^{*} \\
(0.001)\end{array}$ & & $\begin{array}{c}0.001 \\
(0.001)\end{array}$ \\
\hline Constant & $\begin{array}{c}10.262^{* * *} \\
(0.008) \\
\end{array}$ & $\begin{array}{c}10.387^{* * *} \\
(0.009) \\
\end{array}$ & $\begin{array}{c}9.816^{* * *} \\
(0.297) \\
\end{array}$ & $\begin{array}{c}10.479^{* * *} \\
(0.010) \\
\end{array}$ & $\begin{array}{c}10.548^{* * *} \\
(0.292) \\
\end{array}$ \\
\hline Controls? & No & No & Yes & No & Yes \\
\hline Observations & 976 & 976 & 284 & 976 & 306 \\
\hline $\mathrm{R}^{2}$ & 0.400 & 0.283 & 0.670 & 0.173 & 0.564 \\
\hline Residual Std. Error & 0.486 & 0.585 & 0.443 & 0.621 & 0.490 \\
\hline F Statistic & $649.596^{* * *}$ & $385.114^{* * *}$ & $45.855^{* * *}$ & $204.038^{* * *}$ & $31.550^{* * *}$ \\
\hline
\end{tabular}


Table E2-Panel Regression: log(Income Per Capita) (NAICS, $C M_{r, i}$, ECI)

\begin{tabular}{|c|c|c|c|c|}
\hline & \multicolumn{4}{|c|}{ Dependent variable: } \\
\hline & \multicolumn{4}{|c|}{ Income } \\
\hline & $98-15$ & $98-06$ & $07-15$ & $07-15$ \\
\hline & $(1)$ & $(2)$ & $(3)$ & $(4)$ \\
\hline ECI & $\begin{array}{l}-0.003 \\
(0.008)\end{array}$ & $\begin{array}{c}0.040^{* * *} \\
(0.005)\end{array}$ & $\begin{array}{c}-0.021^{* *} \\
(0.008)\end{array}$ & $\begin{array}{c}-0.040^{* * *} \\
\quad(0.009)\end{array}$ \\
\hline Unemployment & & & & $\begin{array}{c}-0.004^{* * *} \\
(0.001)\end{array}$ \\
\hline ManuShare & & & & $\begin{array}{c}0.097^{* *} \\
(0.042)\end{array}$ \\
\hline $\log ($ Patent $)$ & & & & $\begin{array}{l}0.002^{*} \\
(0.001)\end{array}$ \\
\hline Population & & & & $\begin{array}{c}0.062 \\
(0.093)\end{array}$ \\
\hline MedianAge & & & & $\begin{array}{l}-0.001 \\
(0.001)\end{array}$ \\
\hline Education & & & & $\begin{array}{l}-0.0002 \\
(0.0003)\end{array}$ \\
\hline BlackShare & & & & $\begin{array}{c}-0.004^{* * *} \\
(0.001)\end{array}$ \\
\hline Foreign & & & & $\begin{array}{c}0.004^{* * *} \\
(0.001)\end{array}$ \\
\hline UnionCoverage & & & & $\begin{array}{l}0.0001 \\
(0.001)\end{array}$ \\
\hline MinimumWage & & & & $\begin{array}{l}-0.004 \\
(0.003)\end{array}$ \\
\hline Vote & & & & $\begin{array}{c}-0.001^{* * *} \\
(0.0002) \\
\end{array}$ \\
\hline Observations & 17,568 & 8,784 & 8,784 & 2,663 \\
\hline $\mathrm{R}^{2}$ & 0.00002 & 0.006 & 0.002 & 0.085 \\
\hline Adjusted $\mathrm{R}^{2}$ & -0.060 & -0.120 & -0.124 & -0.045 \\
\hline F Statistic & 0.285 & $46.139^{* * *}$ & $12.514^{* * *}$ & $18.047^{* * *}$ \\
\hline
\end{tabular}




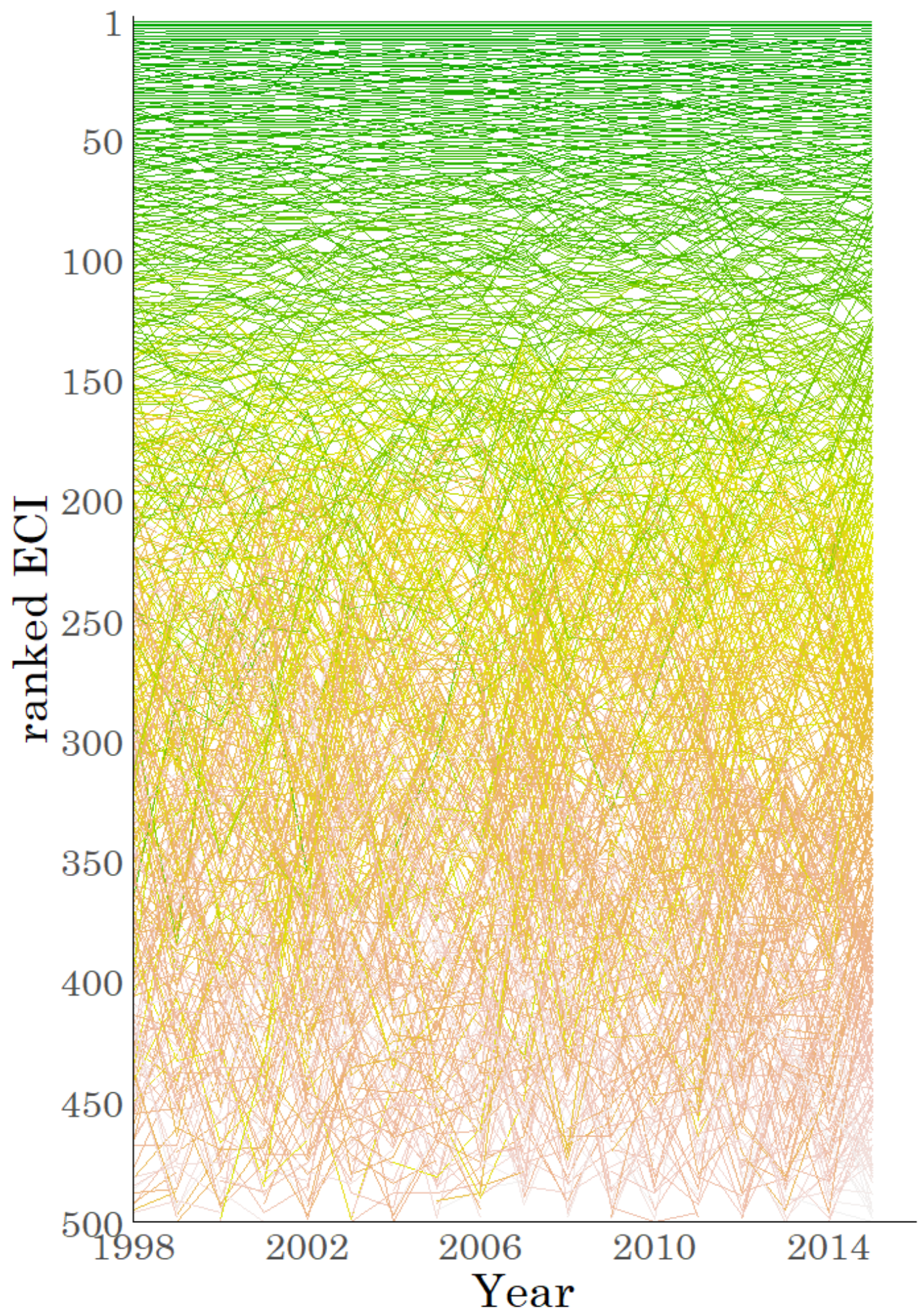

Figure E1. Complexity Rank Changes Between 1998 and 2015: ECI $\left(C M_{r, i}\right.$, SiX-Digit NAICS Industries $)$ 


\section{Appendix F. RoBustness}

\section{F1. ECI computed based on different input matrices \\ SCATTERPlot With MAIN SPECIFICATION}

In Figure F.F1 we look at the correlation between the ECI as computed in our main specification on the one hand and the ECI computed based on our two alternative input matrices, $B M_{r, i}$ and $P M_{r, i}$, on the other hand (all for the year 2015 with 6-digit NAICS level and all industries). Here, we can see that the correlation between ECI computed based on $C M_{r, i}$ and the other two input matrices is very high - at least 0.95 . We remain confident in our choice of the algorithm due to the reasons outlined in section IV.C. However, we expect - based on these results - that the differences between the three input matrices in terms of their relationship with socio-economic variables like income should not be very large. This is what we briefly investigate in the next section.

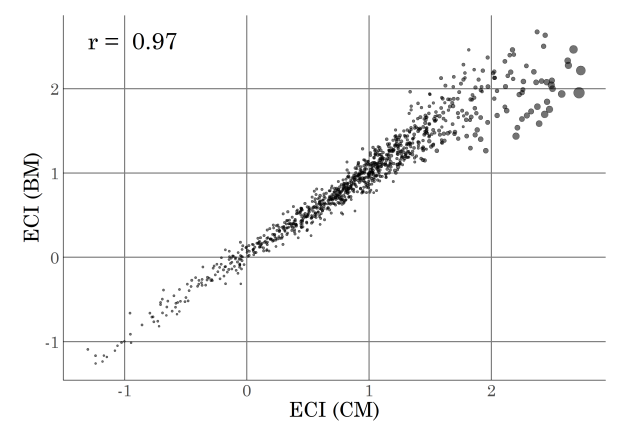

(a) ECI based on $C M_{r, i}$ and $B M_{r, i}$

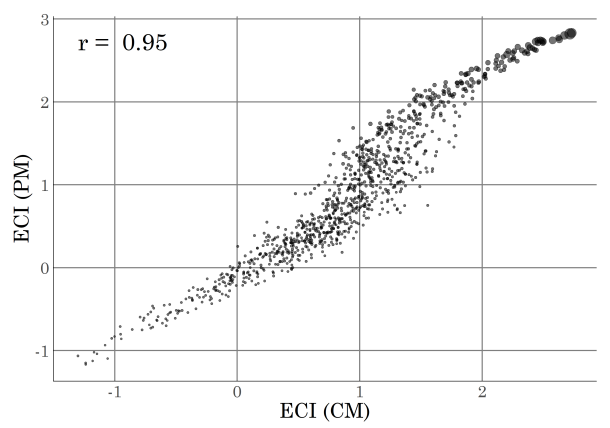

(b) ECI based on $C M_{r, i}$ and $P M_{r, i}$

Figure F1. Scatter Plots of ECI computed based on $C M_{r, i}$ vs. the TWo Other INPUt MATRICES (SiX-Digit NAICS INDUstries, 2015)

Source: Own calculations and CBP.

Plot of CROSS-SECTION REGRESSION EFFECTS

Figure F2 gives the bivariate cross-section effect of ECI in the regression of Income per capita - all based on all industries and on the 6-digit NAICS level. The different panels give the different input matrices $\left(B M_{r, i}, C M_{r, i}, P M_{r, i}\right)$ ECI is computed on. We use no control variables. The error bars are the $99 \%$ confidence intervals.

On the $1 \%$ significance level there are very few differences between the effect size of the ECI computed on the three different industry groupings. If anything, the effect size of ECI computed on the basis of $C M_{r, i}$ is stronger than the other two types. 


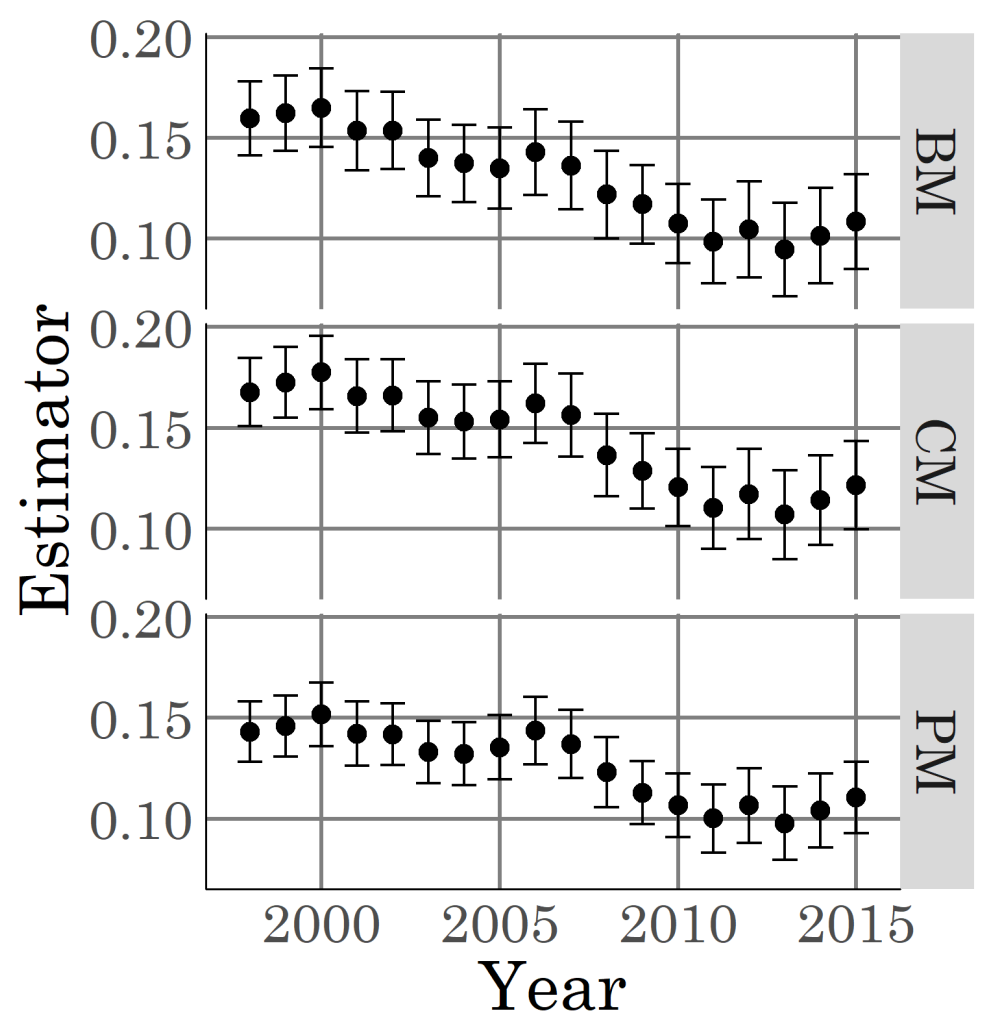

Figure F2. Cross Section Regression of Income on ECI (6digit NAICS, DIFFERENT INPUT MATRICES)

Source: Own calculations and CBP.

\section{F2. ECI for local and traded industries only \\ SCATTERPLOT WITH MAIN SPECIFICATION}

Figure F3 shows the correlation plot (all based on $C M_{r, i}$ and 6-digit NAICS) comparing the main specification (all industries) to specifications limited to local and traded industries respectively for the year 2015. Both correlations are very high (at 0.84 and 0.92 respectively). If anything, ECI on our main specification is somewhat more correlated to the ECI build based on traded industries only, i.e. the ranking done by the complexity algorithm is more similar between all and traded industries than between traded and local industries.

\section{PLOT OF CROSS-SECTION REGRESSION EFFECTS}

Figure F4 gives the bivariate cross-section effect of ECI in the regression of Income per capita - again all based on $C M_{r, i}$ and on the 6digit NAICS level. The different facets give the different industry groups (all, local, traded) ECI is computed on. We use no control variables. The error bars are the $99 \%$ confidence intervals. 


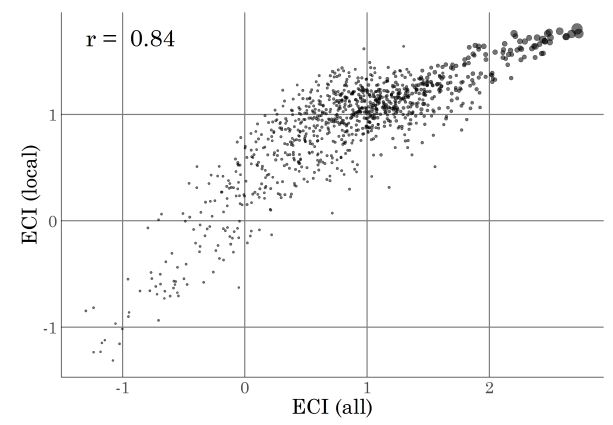

(a) ECI main specification with local industries

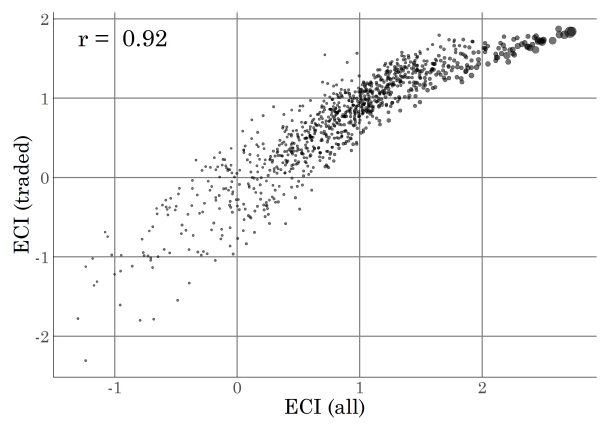

(b) ECI main specification with traded industries

Figure F3. Scatterplot ECI All industries vs LOCAL/Traded indusTRIES $\left(C M_{r, i}\right.$, NAICS, 6DIGIT) - 2015

Source: Own calculations and CBP.

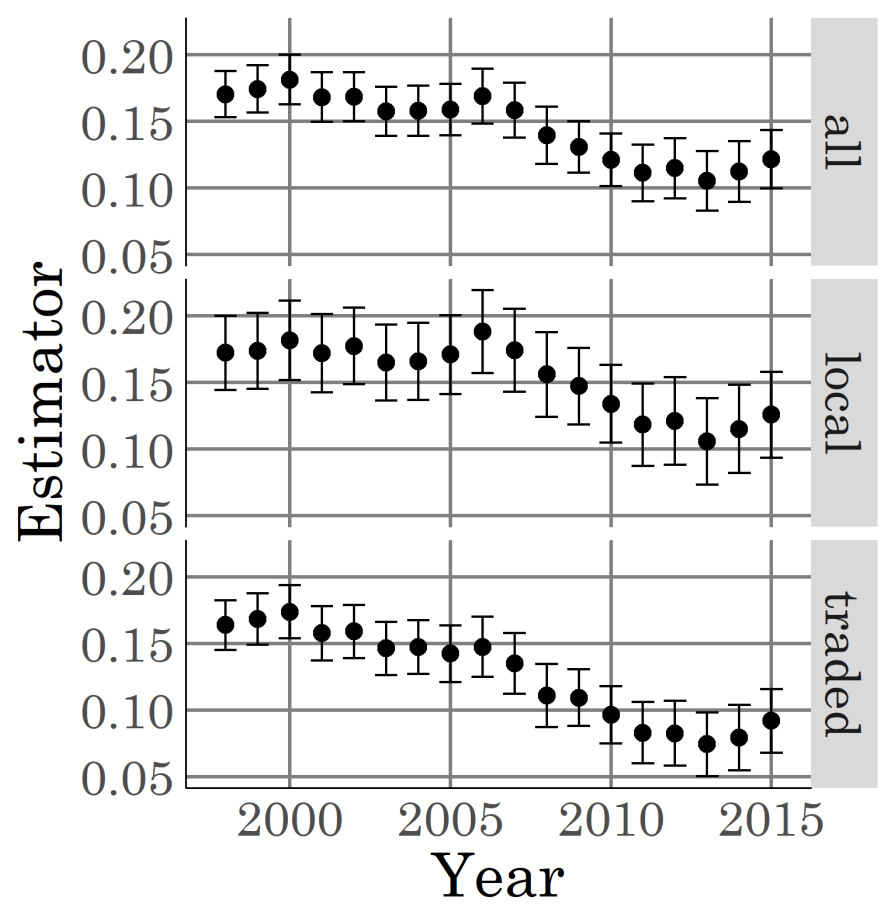

Figure F4. Cross Section Regression of Income on ECI $\left(C M_{r, i}\right.$, DifFERENT INDUSTRY GROUPS, 6DIGIT NAICS INDUSTRIES) 
On the $1 \%$ significance level there are very few differences between the effect size of the ECI computed on the three different industry groupings. If anything, the effect size of ECI computed by local industries is stronger than the other two types. On the $5 \%$ significance level (not shown here), these differences would be often significant.

\section{F3. Fitness Index}

SCATTERPLOT WITH MAIN SPECIFICATION

Figure F5 plots regional ECI in 2015 from our preferred specification $\left(C M_{r, i}\right.$, six-digit NAICS industries) against the $\log$ of regional $F I$ calculated from the same input matrix. As the figure shows, ECI and FI are strongly correlated, at roughly 0.94 .

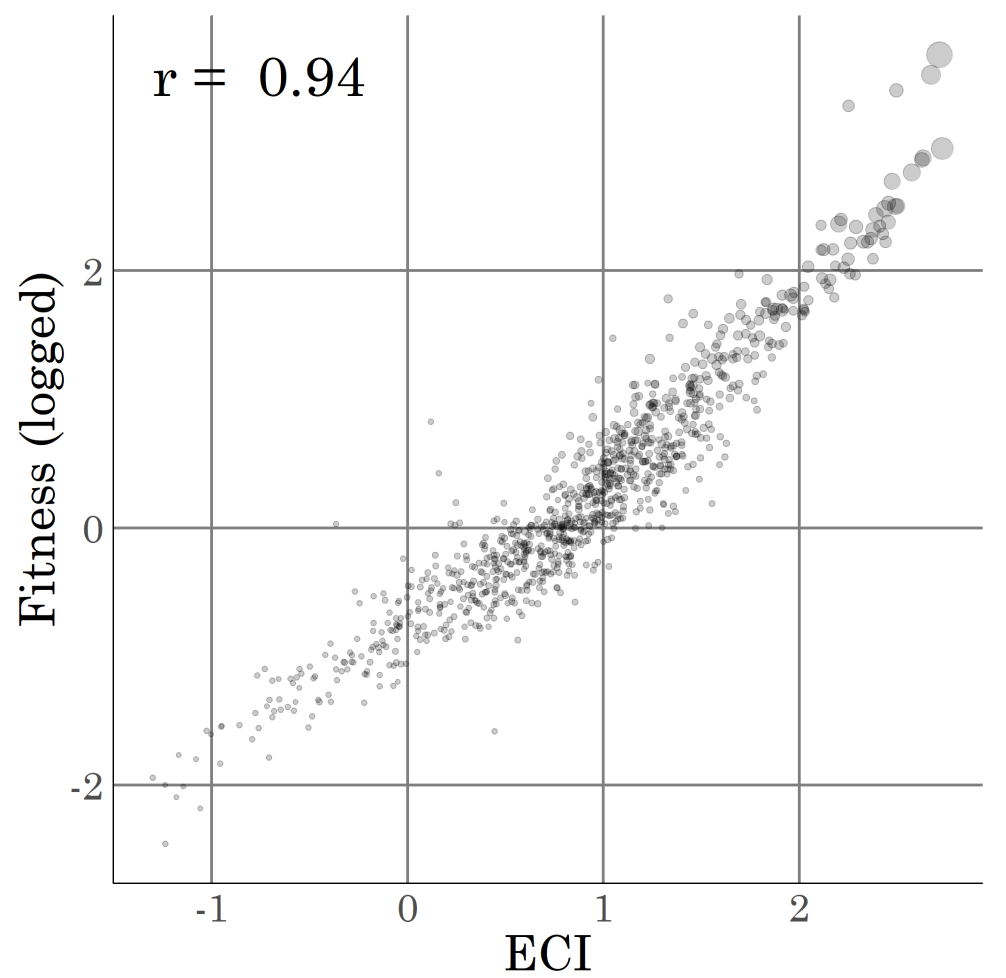

Figure F5. ECI vs Logged FI $\left(C M_{r, i}\right.$, SiX-Digit NAICS Industries, 2015) Source: Own calculations and CBP.

PLOT OF CROSS-SECTION REGRESSION EFFECTS

Figure F6 gives the bivariate cross-section effect of ECI and Fitness respectively in the two seperate regressions of Income per capita - again all based on $C M_{r, i}$ 
and on the 6digit NAICS level. The different facets give the effect of ECI and Fitness respectively. We use no control variables. The error bars are the $99 \%$ confidence intervals.

Also Fitness as a positive and significant coefficient. However, On the $1 \%$ significance level the effect of ECI is almost always significantly bigger.

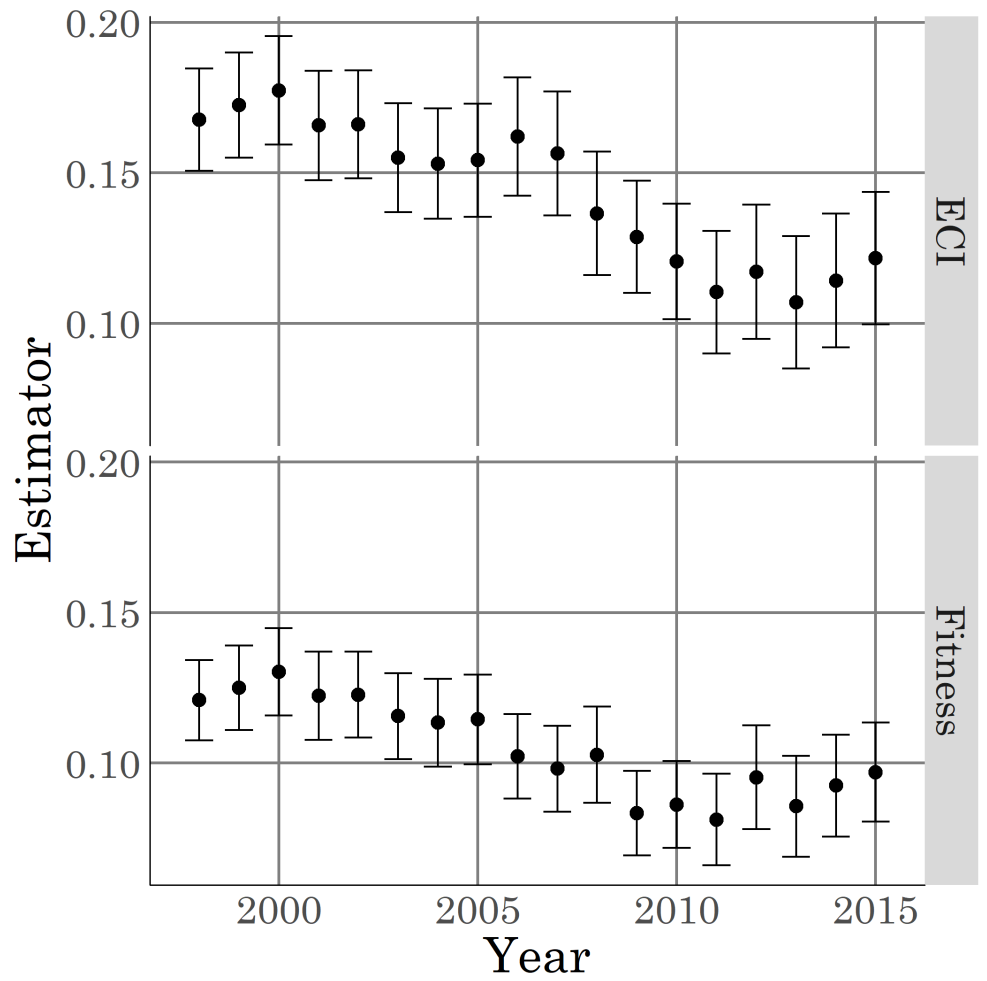

Figure F6. Cross Section Regression of Income on ECI and Fitness $\left(C M_{r, i}\right.$, DIFFERENT INDUSTRY GROUPS, 6Digit NAICS INDUSTRIES)

Source: Own calculations and CBP.

\section{F4. ECI on different NAICS digit levels}

SCATTERPLOT WITH MAIN SPECIFICATION

Figure F7 shows the correlation between ECI computed with 2- to 5-digit NAICS codes and our primary, 6-digit NAICS, specification (all based on $C M_{r, i}$ and all industries). There is a very strong correlation (0.99) between the 5- and 6digit levels, and only a slightly weaker correlation (0.94) between 4- and 6-digit levels. At the 3-digit level the relationship weakens, with variation among highcomplexity metros in particular no longer being captured (the overall correlation between 3 - and 6 -digit levels is 0.88 ). At the 2 digit the relationship largely breaks 
down: the overall correlation is only 0.47 , and the 2-digit specification has difficulty discerning variations among the top half of metros. Overall, we consider the three most disaggregated digit levels roughly equivalent and stick to the highest resolution (6-digit) in order to make use of as much information as possible. This is notable because previous studies of economic complexity in the United States have often used industries at the 2- or 3-digit level.

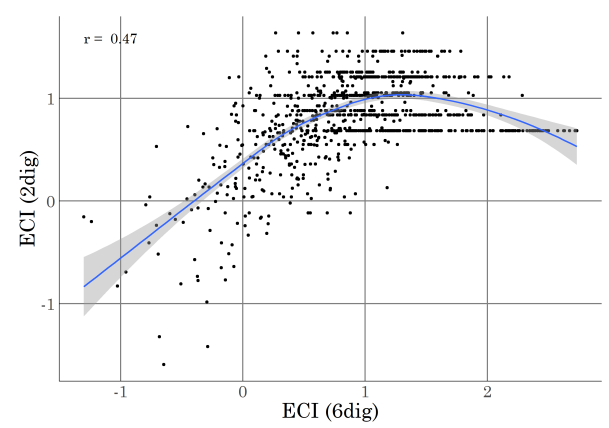

(a) 2 and 6 digit

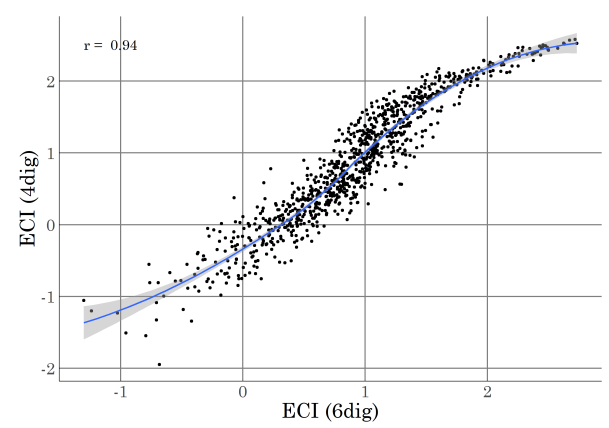

(c) 4 and 6 digit

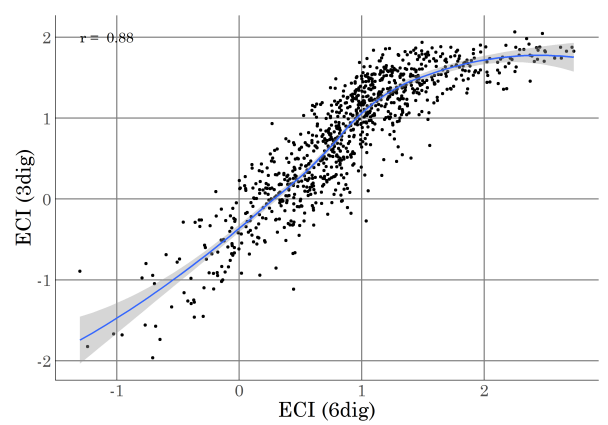

(b) 3 and 6 digit

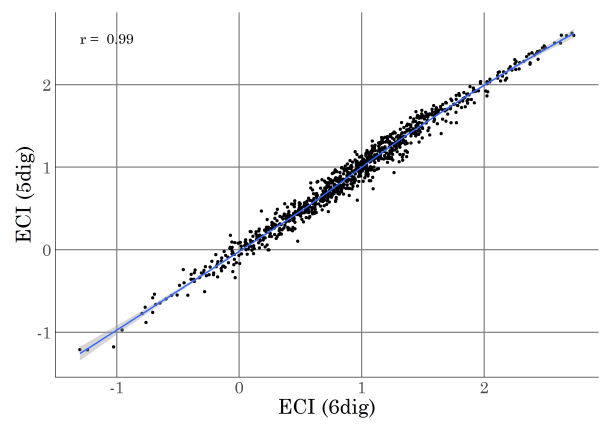

(d) 5 and 6 digit

Figure F7. Scatterplot ECI based on Different NAICS Digits $\left(C M_{r, i}\right.$, 2015)

Source: Own calculations and CBP.

\section{PLOT OF CROSS-SECTION REGRESSION EFFECTS}

Figure F8 gives the bivariate cross-section effect of ECI in the regression of Income per capita - again all based on $C M_{r, i}$ and all industries. The different facets give the different NAICS digit levels ECI is computed on. We use no control variables. The error bars are the $99 \%$ confidence intervals.

The core take-aways are that a) ECI on all digit levels in all years is a positive significant regressor b) the effect size of ECI on the 6 and 5 digit level is in almost all years significantly (we still plot $99 \%$ confidence intervals) higher than 
their correspondents on the 2-4 digit level. Furthermore, c), the drop in effect size around the year 2007 which we can observe for the 5 and 6 digit level is less pronounced on the lower levels. Finally, d), there is no significant difference between the 5 and 6 digit level.

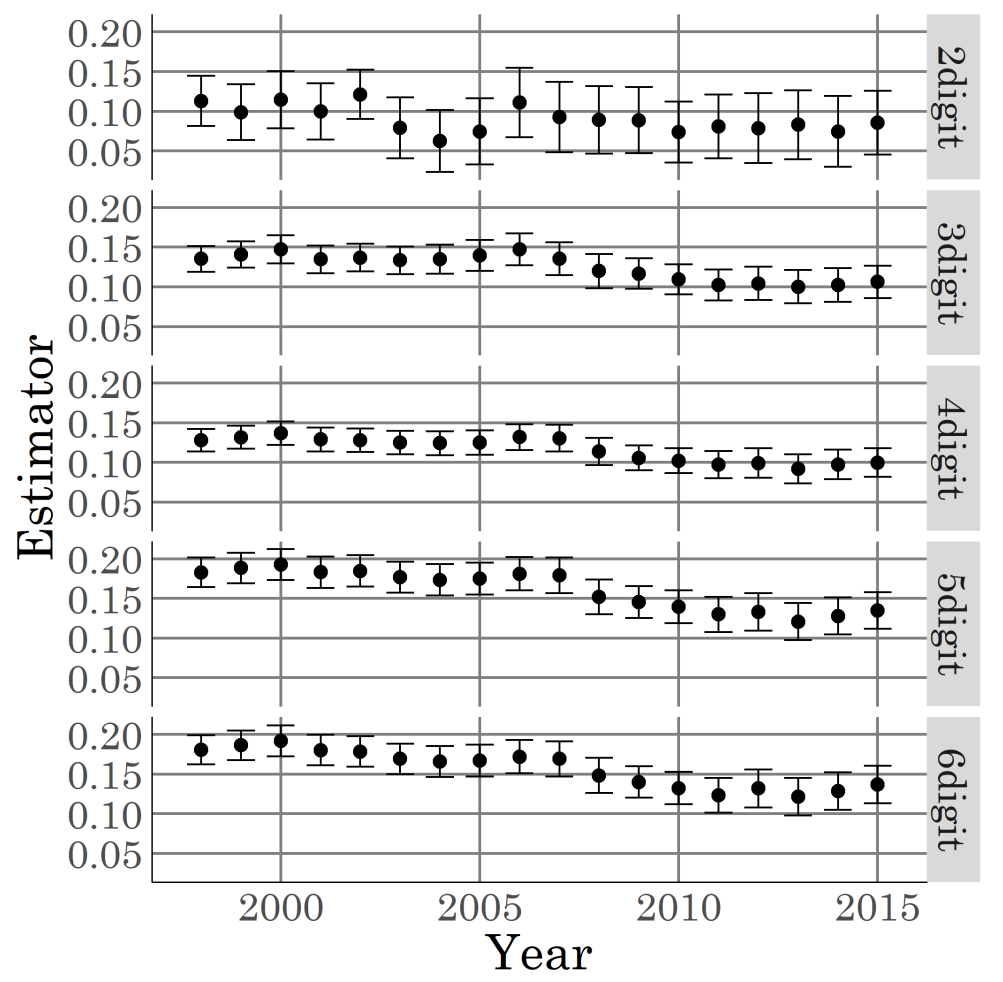

Figure F8. Cross Section Regression of Income on ECI $\left(C M_{r, i}\right.$, DifFERENT DIGITS, NAICS INDUSTRIES) 